DIW BERLIN

Discussion

Papers

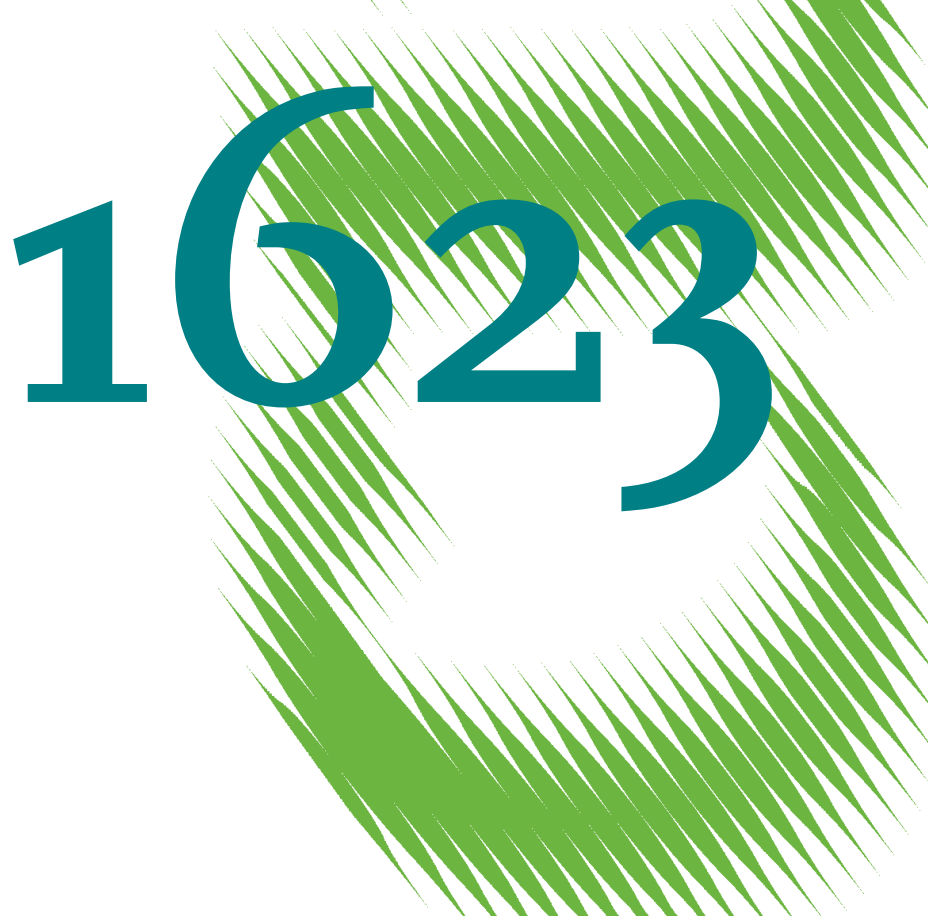

The Signaling Role of Fiscal Austerity 
Opinions expressed in this paper are those of the author(s) and do not necessarily reflect views of the institute.

IMPRESSUM

(C) DIW Berlin, 2016

DIW Berlin

German Institute for Economic Research

Mohrenstr. 58

10117 Berlin

Tel. +49 (30) $89789-0$

Fax +49 (30) $89789-200$

http://www.diw.de

ISSN electronic edition 1619-4535

Papers can be downloaded free of charge from the DIW Berlin website:

http://www.diw.de/discussionpapers

Discussion Papers of DIW Berlin are indexed in RePEc and SSRN:

http://ideas.repec.org/s/diw/diwwpp.html

http://www.ssrn.com/link/DIW-Berlin-German-Inst-Econ-Res.html 


\title{
The Signaling Role of Fiscal Austerity
}

\author{
Anna Gibert ${ }^{\dagger}$
}

15 July 2016

\begin{abstract}
I build a model where creditworthy countries may use fiscal austerity to communicate their ability to repay sovereign debt and show that the signaling channel is active only for high levels of asymmetric information. The model generates a negative association between the amount of public information, provided by the rating agencies, and fiscal tightness. Informed by the model predictions, I perform an empirical investigation based on a panel of 58 OECD and emerging market economies since 1980 and find evidence of this signaling channel.
\end{abstract}

JEL Classification: D82; E62; F34; G24.

Keywords: signaling; fiscal austerity; sovereign debt; credit ratings.

\footnotetext{
${ }^{\dagger}$ German Institute for Economic Research (DIW). Mohrenstraße 58, 10115 Berlin, Germany. Email: agibert@diw.de. I am grateful to my supervisors Piero Gottardi and Árpád Ábrahám for their continued support and advice. I am also indebted to Thomas F. Cooley for his invaluable help. I thank Laura Veldkamp, Ana Fostel, Christoph Trebesch, Isaac Baley, Andrew Gimber, Vincent Maurin, Tommaso Oliviero, Patricia Gomez-Gonzalez and the participants at the EUI working group, the NYU macro student lunch, research seminars at Banco de España, DIW, Malaga University and the $18^{\text {th }}$ Conference in Theories and Methods in Macroeconomics, the $2^{\text {nd }}$ Macro Banking and Finance Workshop, the $12^{\text {th }}$ International Paris Finance Meeting and the XXXIX Simposio de la Asociación Española de Economía-Spanish Economic Association (SAEe) for their helpful comments. All remaining errors are my own.
} 


\section{Introduction}

In this paper, I investigate the role of fiscal austerity as a way to communicate a sovereign's ability to honor the debt. Austerity is at the forefront of the public policy debate following the European sovereign debt crisis. It refers to a combination of measures that reduce a country's deficit, hence, the debt burden. Most of the discussion about austerity measures revolved around the issue of debt sustainability (ECB, 2012; StLouisFED, 2012).However, a number of countries engaging in sizable austerity after 2010 were thought to be in the safe European "core." For instance, Germany announced plans to reduce its budget deficit by 80 billion euros by 2014. The UK embarked on the biggest cuts in state spending since World War II, while the Netherlands also went through several austerity packages despite a relatively low ratio of debt to GDP. ${ }^{1}$ The argument advocated by policymakers is that such measures reassured the markets about the country's creditworthiness and helped maintain access to international lending. In the words of German Chancellor Angela Merkel, "austerity measures are adopted in order to send a very important signal," ${ }^{2}$ or, as the British Chancellor of the Exchequer George Osborne put it, "we have to convince the world that we can pay our way in the world." 3

In the first part of this paper I build a model of sovereign debt that incorporates a signaling role for fiscal austerity. Countries differ in their ability to repay their sovereign debt. The key feature is that the ability to pay is unobservable; hence, it means that lenders cannot differentiate between different types of countries. For example, one could think of these types as reflecting the varied political preferences of citizens with respect to the tradeoff between public spending and debt repayment. Some countries are more resistant than others at accepting tax increases or expenditure reductions. Although attempts to cut public wages and reform the pension system were met with social protest in Portugal and had to be abandoned, ${ }^{4}$ similar measures were successfully implemented in other countries, including Italy and Spain. An alternative way to view these types is related to a country's degree of tax evasion. Sovereigns might not be equally efficient at levying taxes or fighting tax evasion, so their ability to repay debt is limited accordingly.

The economic mechanism is similar to Spence's signaling model of education (Spence, 1973), in which a more able individual has a lower cost of completing an action (getting education) and uses this choice to convey information about his/her ability. However, unlike with Spence's signal, the choice of debt in my model also has a direct effect on the ability

\footnotetext{
1 "EU austerity drive country by country," BBC News, 21 May 2012.

2 "Merkelettes' Siren Song Sounds Very German," The Wall Street Journal, 12 July 2011.

3 "Sterling hits two-year low after Moody's UK downgrade," The Telegraph Investor, 25 February 2013.

4 "Portugal court rules public sector pay cut unconstitutional," BBC News, 6 July 2012.
} 
to repay. I derive the conditions that imply the single-crossing property, which enables me to find a separating equilibrium. The separating equilibrium outcome is the following: more creditworthy countries choose to issue less debt than the optimum level under full information. A sufficient amount of austerity makes less able countries unwilling to imitate this strategy; hence, the market rewards austerity with a lower risk premium on sovereign debt. The model admits other equilibria as well. Selection is made using the undefeated equilibrium refinement by Mailath et al. (1993). This concept is particularly useful for analyzing the welfare properties of equilibria (Sobel, 2009). In my model, the refinement delivers a sharp empirical prediction: the nature of the equilibrium that prevails - separating or pooling- is uniquely determined by the amount of information about the country type. I show how the amount of information changes with the introduction of sovereign ratings and conclude that less informative ratings are linked to increases in austerity for signaling purposes.

In the empirical section, I perform an analysis of a panel of 58 countries since the 1980s to find evidence of the signaling channel. The focus is on two indicators of the amount of public information about a country creditworthiness: (1) the cross-sectional correlation between sovereign yields and sovereign ratings over time; and (2) a dummy for extreme sovereign yield changes conditional on the rating category. Using time and rating-varying indicators of informativeness, I exploit the panel dimension of the data to determine changes in austerity. I also use the fact that the overall informativeness of the ratings is not likely to be affected by an individual country's choice of fiscal policy. Five variables measure fiscal austerity: (1) the cyclically adjusted primary balance (CAPB); (2) the government net borrowing; (3) the net primary balance; (4) public spending; and (5) a dummy variable for fiscal consolidations that is based on the narrative approach of Devries et al. (2011). I find that the correlation between sovereign yields and ratings is negatively associated with all the measures of fiscal austerity. The coefficient remains significantly different than zero after controlling for other variables that are usually used in the literature estimating fiscal rules (Gali and Perotti, 2003; Favero and Monacelli, 2005; Baldacci et al., 2013). Further robustness checks evaluate alternative hypotheses and favor the signaling channel as the most compelling explanation of the evidence.

Literature review. A few other works consider incomplete information in a model of sovereign debt (Sandleris, 2008; Drudi and Prati, 2000; Fostel et al., 2013). Although some of them explore signaling, none of the above is primarily concerned with the role of austerity as a signal. The closest article to mine is Dellas and Niepelt (2014), who provide a formal definition of austerity in the context of incomplete information as "the shortfall of consumption from the level desired by a country and supported by its repayment capacity." 
In my set-up, this "consumption gap" maps into a "debt gap." Dellas and Niepelt (2014) consider several instruments a country might use to signal its creditworthiness, especially public investment, and argue that, in some cases, signaling might be associated with austerity. Instead, I shift the attention to austerity as the instrument for signaling and then incorporate the sovereign ratings into the model, which allow me to perform an empirical analysis based on the predictions of the model.

The empirical exercise in this paper is related to a large body of literature that documents the changes in the informativeness of the credit ratings over time (Partnoy, 2006; Kiff et al., 2012; Bussiere and Ristiniemi, 2012; De Santis, 2012). I abstract from the various explanations advanced to motivate the shifts in informativeness ${ }^{5}$ and link the changes in my two indicators of informativeness to the changes in austerity made by a given country. To the best of my knowledge, this is the first empirical evidence of the signaling channel in fiscal policy.

The paper is organized as follows. In the next section I present the model and in Section 3 I characterize the equilibrium set. Sovereign credit ratings are introduced in Section 4.1, while Section 4.2 extends the model to multiple periods. Section 5 is devoted to the empirical analysis. Section 6 concludes.

\section{Model}

Consider a two-period small open economy where a sovereign borrower issues debt to foreign lenders in order to maximize its citizens welfare. ${ }^{6}$ The sovereign country has limited commitment, defaulting whenever it is unable to fully repay its debt. Depending on its ability to repay, the sovereign can be of two types, indexed by $i \in\{A, B\}$ with probability $p$ and $1-p$ respectively. Foreign lenders do not know what type of borrower the country is.

Lenders' problem. Lenders are risk-neutral. They lend the amount $q D_{2}$ in period 1 to the sovereign, where $q$ is the price of debt in period 1. If there is no default, they receive $D_{2}$ in period 2. In case of default, there is no partial repayment. The lender profit function is:

$$
\Pi=-q D_{2}+\beta^{\prime} D_{2}\left[1-\lambda\left(D_{2}, \mu\right)\right]
$$

\footnotetext{
${ }^{5}$ A non-exhaustive list of contributions include Bar-Isaac and Shapiro (2013); Holden et al. (2012); Manso (2013); Mathis et al. (2009); White (2010); Skreta and Veldkamp (2009); Josepson and Shapiro (2014); Opp et al. (2013) and Cole and Cooley (2014).

${ }^{6}$ In the model, sovereign debt is equivalent to external debt. Domestic debt does not play any role in this model because the government has enough instruments to allocate consumption intertemporally for its citizens.
} 
where $\beta^{\prime}$ is the lenders' discount factor, $\mu$ the probability that the borrower is of type A and $\lambda(D, \mu)=[\mu \lambda(D, 1)+(1-\mu) \lambda(D, 0)]$ represents the expected sovereign's default probability at $(D, \mu)$ and will be precisely defined below. Lenders compete à la Bertrand over lending conditions driving profits to zero. As a result, the equilibrium price function satisfies:

$$
q\left(D_{2}, \mu\right)=\beta^{\prime}\left[1-\lambda\left(D_{2}, \mu\right)\right]
$$

The sovereign debt price responds to the amount of debt issued and the lenders' belief about creditworthiness. The higher the price is, the more advantageous are the borrowing terms for the sovereign.

Sovereign's problem. The problem solved by the sovereign government is to maximise citizens' expected discounted utility $c_{1}+\beta \mathbb{E}\left[c_{2}\right]$, where $\beta$ is the discount factor. The representative citizen has endowment $\omega_{1}$ in period 1 , and a random endowment $\omega_{2}$ in period 2 , which is drawn from an exponential distribution $f\left(\omega_{2}\right)$ with support $[\underline{\omega}, \infty)$, hazard rate $h$ and cumulative function $F\left(\omega_{2}\right) \cdot{ }^{7}$ Given the initial level of debt $D_{1}$, the sovereign government chooses the debt level $D_{2}$ and taxes $T_{1}, T_{2}$ to satisfy the government budget.

Each country, of type $i=A, B$, that repays its debt satisfies the following constraints:

$$
\begin{aligned}
c_{t} & \leq \omega_{t}-T_{t}, \quad \text { for } t=1,2 \\
T_{1} & \geq D_{1}-q\left(D_{2}, \mu\right) D_{2} \quad \text { and } \quad T_{2} \geq D_{2} . \\
c_{t} & \geq \underline{c}^{i} \text { for } t=1,2 .
\end{aligned}
$$

Constraint (2.3) is the budget constraint of the respective citizens. Constraints (2.4) represent the government budget constraint in $t=1,2$. The initial level of debt $D_{1}$ is exogenous and $D_{3}=0$ since in the last period debt cannot be rolled over. It is easy to see that both (2.3) and (2.4) will be satisfied with equality. Hence, once the choice of $D_{2}$ is taken, taxes and consumption in $t=1$ are fully pinned down under repayment. Constraint (2.5) introduces heterogeneity in the ability to pay across countries. It states that the sovereign government must guarantee to its citizens a consumption level of $\underline{c}^{i}$ every period. Differences in the guaranteed level of consumption are the only source of ex-ante heterogeneity across countries.

I assume

$$
\underline{c}^{A}<\underline{c}^{B}
$$

Constraint (2.5), together with the budget constraint (2.3), imposes a cap on the ability

\footnotetext{
${ }^{7}$ The exponential function $f(\omega)=h e^{-h \omega}$ features a constant hazard rate, which is helpful in order to obtain the same level of equilibrium debt for both types under full information.
} 
to tax. Since $\underline{c}^{B}$ is higher than $\underline{c}^{A}$, country B is less able to repay the outstanding debt than country A for the same level of income. Stated differently, ceteris paribus, country B is less creditworthy.

In order to always guarantee the existence of a feasible allocation I also assume the following

$$
\underline{\omega} \geq \underline{c}^{B}
$$

I assume away strategic default. Since $\omega_{2} \in[\underline{\omega}, \infty)$, in the first period, a country will never default. Default will occur in period 2 for $\omega_{2} \leq D_{2}+\underline{c}^{i}$. If the second period endowment realization does not suffice to cover both the commitments versus foreign lenders and the domestic commitments on citizens' required consumption, the country defaults on its debt. Otherwise the country complies with its commitment. The probability of default for country $i=A, B$, with debt level $D_{2}$ is hence $F\left(D_{2}+\underline{c}^{i}\right)$.

Our analysis will be confined to the range of parameters that satisfy

$$
\underline{c}^{B}>\frac{\omega_{1}-D_{1}+\beta^{\prime} \underline{\omega}}{1+\beta^{\prime}} .
$$

This condition rules out the uninteresting case in which the two types have zero probability of default. ${ }^{8}$ By assumption (A1), $F\left(D_{2}+\underline{c}^{A}\right) \leq F\left(D_{2}+\underline{c}^{B}\right) \forall D_{2}$ and, by (A3), the inequality is strict. For any given debt level, a type A country is less prone to default. This predisposition to default is driven by unobservable fundamentals of the country - $\underline{\mathrm{c}}_{i}$ - but the type that actually defaults depends on the equilibrium choices and, ultimately, the endowment realization.

In case of default, the citizens consumption is assumed to be $\underline{c}^{i}$ and the lenders do not receive any repayment. The difference between the endowment realization and consumption after default, $\omega_{2}-\underline{c}^{i}$, is a deadweight loss. Finally, I assume

$$
\beta^{\prime}>\beta \cdot \frac{1-F\left(D_{2}+\underline{c}^{A}\right)}{1-F\left(D_{2}+\underline{c}^{B}\right)}=\beta \cdot e^{h\left(\underline{c}^{B}-\underline{c}^{A}\right)} .
$$

Thanks to the exponential assumption, we can state this condition as a function of exogenous parameters. Since $e^{h\left(\underline{c}^{B}-\underline{c}^{A}\right)}>1$, it implies that the discount factor abroad $\beta^{\prime}$ is higher than the domestic discount factor $\beta$ by a wedge that is high enough to compensate for the difference in risk premia across types. External lenders are willing to finance a type B sovereign at a rate that is attractive domestically for both types. This makes a sovereign country willing

\footnotetext{
${ }^{8}$ The maximum level of debt that allows country B to be risk free in the second period is $D_{2}=\underline{\omega}-\underline{c}^{B}$. Assume that this level (or a lower one) would be unfeasible in the first period at the risk-free price $\beta^{\prime}$ : $\underline{c}^{B}>\omega_{1}-D_{1}+\beta^{\prime}\left(\underline{\omega}-\underline{c}^{B}\right)$, or reformulated, $\underline{c}^{B} \geq \frac{\omega_{1}-D_{1}+\beta^{\prime} \underline{\omega}}{1+\beta^{\prime}}$. Assumptions (A3) and (A2) are compatible as long as $\underline{\omega} \geq \omega_{1}-D_{1}$.
} 
to increase period 1 consumption and finance it by issuing new debt. ${ }^{9}$ What remains to be determined is how much new debt the country wants to issue, once it internalizes that issuing debt changes the relative price of debt versus repayment. And this choice can be made contingent on the type.

Single crossing. Combining the previous ingredients, the discounted expected utility of sovereign $i$ is:

$$
\begin{aligned}
U^{i}\left(q, D_{2}\right) & :=\omega_{1}-D_{1}+q D_{2} \\
& +\beta\left[F\left(D_{2}+\underline{c}^{i}\right) \underline{c}^{i}+\left(1-F\left(D_{2}+\underline{c}^{i}\right)\right)\left(\mathbb{E}\left[\omega_{2} \mid \omega_{2} \geq D_{2}+\underline{c}^{i}\right]-D_{2}\right)\right] .
\end{aligned}
$$

The first line of the right-hand side represents the citizens' consumption in the first period: the endowment $\omega_{1}$ plus the net borrowing of the period. The second line represents the expectation of consumption in period 2 discounted by $\beta$ : with probability $F\left(D_{2}+\underline{c}^{i}\right)$, the country defaults and consumption is $\underline{c}^{i}$, and with the complementary probability, consumption is the result of the endowment, noticing that $\omega_{2}$ can only be a realization compatible with repayment, minus the debt outstanding. Expression (2.6) can be used to define the indifference curves in the space of two key variables $\left(D_{2}, q\right)$. Those indifference curves are represented in figure 1 for the two types of countries.

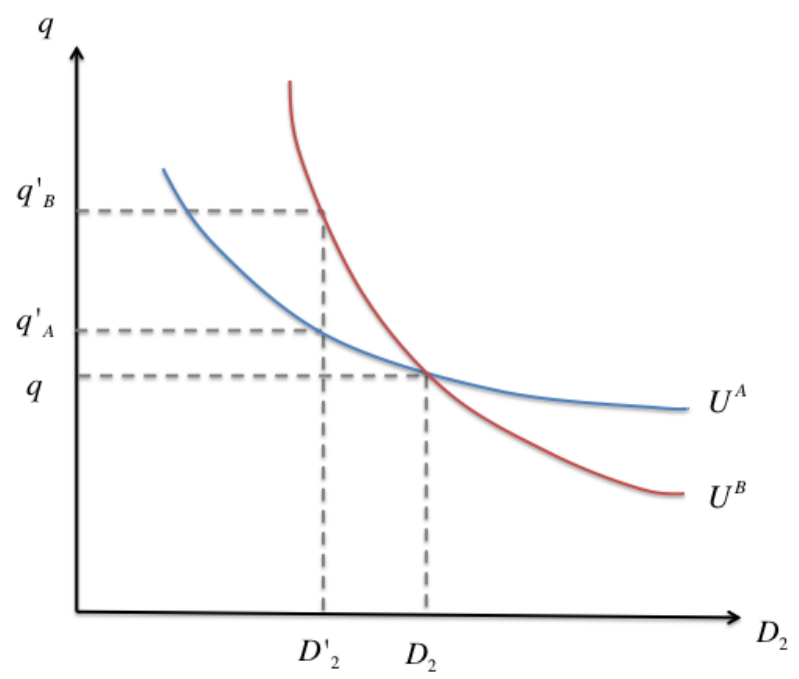

Figure 1: Single crossing property of the preferences.

As explained below, for all $D_{2}$, the slope of type B's indifference curves in $\left(D_{2}, q\right)$ is

\footnotetext{
${ }^{9}$ I choose to motivate the willingness to issue debt by making international credit relatively cheap domestically. Other authors achieve the same result with different assumptions: for example, assuming the government has to finance an investment project that pays in the future (Sandleris, 2008) or that officemotivated politicians like debt (Acharya and Rajan, 2011).
} 
steeper than that of type A. A decrease from $D_{2}$ to $D_{2}^{\prime}$, as depicted in figure 1 , needs to be compensated with an increase from $q$ to $q_{A}^{\prime}$ for type A and from $q$ to $q_{B}^{\prime}$ for type B. This implies that any two curves of $\mathrm{A}$ and $\mathrm{B}$ can cross at most once in the space $\left(D_{2}, q\right)$. The reason behind it is that default occurs when a country cannot afford repayment and, as this depends only on solvency, B can do it more often. ${ }^{10}$ Hence, a type B country benefits more from debt because it anticipates that it has to pay back less. A formal proof of the single-crossing property can be found in Appendix A.

\section{Equilibrium analysis}

\subsection{Full information}

As a benchmark, let us describe the equilibrium of the model when the type of the country is observable. The full information equilibrium allocation is a price and a debt level for each type. In this case, the lenders know type $i$ 's probability of default for each level of debt and charge the actuarially fair price $q^{i}\left(D_{2}\right)=\beta^{\prime}\left[1-F\left(D_{2}+\underline{c}^{i}\right)\right]$. The sovereign faces the price schedule $q^{i}\left(D_{2}\right)$ and maximises the discounted expected utility (equation (2.6)):

$$
\max _{D_{2}} \quad \omega_{1}-D_{1}+q^{i} D_{2}+\beta\left[F\left(D_{2}+\underline{c}^{i}\right) \underline{c}^{i}+\left(1-F\left(D_{2}+\underline{c}^{i}\right)\right)\left[\mathbb{E}\left(\omega_{2} \mid \omega_{2} \geq D_{2}+\underline{c}^{i}\right)-D_{2}\right]\right]
$$

subject to $q^{i}\left(D_{2}\right)=\beta^{\prime}\left[1-F\left(D_{2}+\underline{c}^{i}\right)\right]$.

The first order condition (FOC) with respect to $D_{2}$ is the following:

$$
\frac{\partial q^{i}\left(D_{2}\right)}{\partial D_{2}} D_{2}+q^{i}\left(D_{2}\right)-\beta\left(1-F\left(D_{2}+\underline{c}^{i}\right)\right)=0
$$

The first term in (3.2) represents the change in cost that every inframarginal unit of debt experiences when an additional unit is issued. The second term is the gain from bringing consumption to the present at the current price $q^{i}\left(D_{2}\right)$. Finally, the third term represents the cost of the repayment promise: each unit of debt will be repaid in the next period only if there is no default, which happens with probability $1-F\left(D_{2}+\underline{c}^{i}\right)$.

Substituting the price schedule $q^{i}\left(D_{2}\right)$ in the FOC, after some transformations, we ob-

\footnotetext{
${ }^{10}$ Note that the penalty for default is higher for type A, $\underline{c}^{A}-\omega_{2}-D_{2}<\underline{c}^{B}-\omega_{2}-D_{2} \forall D_{2}$. However, the single crossing property does not require heterogeneous penalty across types. The penalty could be made equal, provided it is not high enough to prevent any default, and type B would still default in more states than A because default is not strategic.
} 
tain: ${ }^{11}$

$$
D_{2}^{i}=\frac{\beta^{\prime}-\beta}{\beta^{\prime}}\left[\frac{F^{\prime}\left(D_{2}^{i}+\underline{c}^{i}\right)}{1-F\left(D_{2}^{i}+\underline{c}^{i}\right)}\right]^{-1} .
$$

And, recalling that $h$ is the hazard rate of the endowment exponential distribution $f(\cdot)$, equation (3.3) simplifies to:

$$
D_{2}^{A}=D_{2}^{B}=\frac{\beta^{\prime}-\beta}{\beta^{\prime} h}
$$

The expression (3.4) is the optimal level of debt under full information. Call the full information equilibrium debt level $D_{2}^{F I} \cdot D_{2}^{F I}$ is positive because of assumption (A4). It means that the country issues a positive amount of debt in order to take advantage of the favourable lending conditions. Despite $D_{2}^{F I}$ is the same for both types, in equilibrium, different types face a different price. Price is lower for type B because this type defaults more than the other, so its debt carries a higher risk premium:

$$
\begin{aligned}
q^{B}\left(D_{2}^{F I}\right) & =\beta^{\prime}\left[1-F\left(D_{2}^{F I}+\underline{c}^{B}\right)\right] \\
& <\beta^{\prime}\left[1-F\left(D_{2}^{F I}+\underline{c}^{A}\right)\right]=q^{A}\left(D_{2}^{F I}\right) .
\end{aligned}
$$

\subsection{Incomplete information}

Consider a game where the type of sovereign is unobservable. Nature draws a type A with probability p. A sovereign knows its type and chooses how much debt to issue, balancing the benefits of increasing present consumption and the probability of future default. The sovereign also takes into account that its choice of debt may reveal information about its type to the uninformed lenders and, therefore, influence their pricing decisions.

The country's strategy is a choice of debt $D_{2}^{*}$. The lenders' strategy is a price function that depends on the observed $D_{2}^{*}$ as well as the lenders' beliefs about the type of the sovereign. The adopted solution concept is the Perfect Bayesian Equilibrium (PBE) in pure strategies.

Definition 3.1. A symmetric PBE in pure strategies is a set of strategies for the sovereign and the lenders,

$$
\begin{aligned}
D_{2}^{*} & :\{A, B\} \rightarrow \mathbb{R} \\
q^{*} & : \mathbb{R} \times[0,1] \rightarrow \mathbb{R}_{+}
\end{aligned}
$$

\footnotetext{
${ }^{11}$ See Appendix B for the proof.
} 
and a system of beliefs $\mu^{*}: \mathbb{R} \rightarrow[0,1]$ on the country being of type $A$, such that:

- For $i=A, B, D_{2}^{*}(i)$ maximises expected utility $U^{i}$ given the lenders' strategy $q^{*}(\cdot)$.

- $q^{*}(\cdot)$ is consistent with zero expected profits: $q^{*}\left(D_{2}, \mu^{*}\right)=\beta^{\prime}\left[1-\lambda\left(D_{2}, \mu^{*}\right)\right] \forall D_{2}, \mu$.

- The system of beliefs $\mu^{*}\left(D_{2}\right)$ is consistent with Bayes' rule and the equilibrium strategies whenever possible. That gives the following equilibrium beliefs function.

- Let $\mathbb{1}_{\{\cdot\}}$ be the indicator function taking the value 1 if the condition in curly brackets holds and zero otherwise.

- If $p \mathbb{1}_{\left\{D_{2}^{*}(A)=D_{2}\right\}}+(1-p) \mathbb{1}_{\left\{D_{2}^{*}(B)=D_{2}\right\}} \neq 0$ then:

$$
\begin{gathered}
\mu^{*}\left(D_{2}\right)=\frac{p \mathbb{1}_{\left\{D_{2}^{*}(A)=D_{2}\right\}}}{p \mathbb{1}_{\left\{D_{2}^{*}(A)=D_{2}\right\}}+(1-p) \mathbb{1}_{\left\{D_{2}^{*}(B)=D_{2}\right\}}}, \\
- \text { If } p \mathbb{1}_{\left\{D_{2}^{*}(A)=D_{2}\right\}}+(1-p) \mathbb{1}_{\left\{D_{2}^{*}(B)=D_{2}\right\}}=0 \text {, then } \mu^{*} \in[0,1] .
\end{gathered}
$$

Separating equilibria. An equilibrium is separating when a sovereign chooses a different debt level depending on its type. Let the equilibrium outcome be the vector of debt levels and prices denoted by $\left\{D_{2}^{*}(i), q^{*}(i)\right\}_{i \in\{A, B\}}$.

A type A country obtains debt at better market conditions because it is less prone to default. Hence, a type B sovereign might have an incentive to pretend to be of type A in order to improve its borrowing terms. To this end, it might choose to mimic type A's strategy. Hence, the relevant incentive compatibility constraint is type B's,

$$
U^{B}\left(D_{2}^{*}(B), q^{*}(B)\right) \geq U^{B}\left(D_{2}^{*}(A), q^{*}(A)\right)
$$

Proposition 3.1. There exists a separating equilibrium outcome $\left(D_{2}^{*}(A), q^{*}(A)\right),\left(D_{2}^{*}(B), q^{*}(B)\right)$, where $D^{*}(B)=D_{2}^{F I}, q^{*}(B)=\beta^{\prime}\left[1-F\left(D_{2}^{*}(B)+\underline{c}^{B}\right)\right]$, $D^{*}(A)=D_{2}^{-B}$ is the level that satisfies (3.5) with equality and $q^{*}(A)=$ $\beta^{\prime}\left[1-F\left(D_{2}^{*}(A)+\underline{c}^{A}\right)\right]$. This is supported by the equilibrium beliefs $\mu^{*}\left(D_{2}^{*}(A)\right)=1$ and $\mu^{*}\left(D_{2}\right)=0$ for $D_{2} \neq D_{2}^{*}(A)$.

Proof. Appendix C.

The allocation $\left(D_{2}^{-B}, q\left(D_{2}^{-B}, 1\right)\right)$, represented in figure 2 , is preferred by A to any other allocation under the price represented by the dotted bold line. At the same time, B is indifferent between that allocation and $\left(D_{2}^{F I}, q\left(D_{2}^{F I}, 0\right)\right)$ by definition. ${ }^{12}$ The intuition is

\footnotetext{
${ }^{12}$ Its incentive compatibility constraint (3.5) is satisfied with equality.
} 


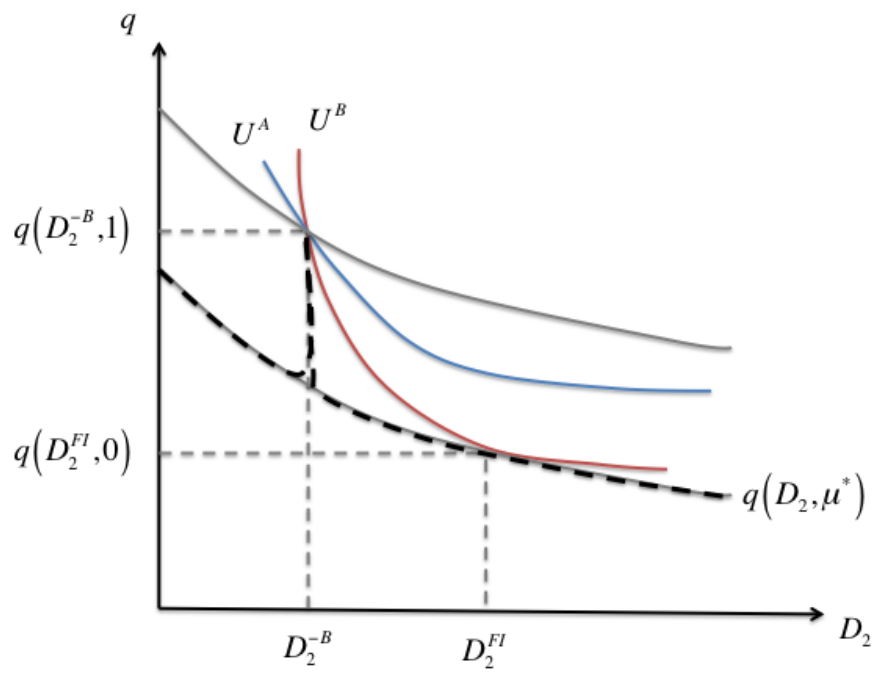

Figure 2: Separating equilibrium $e^{*}$.

that A's isoutility curves in the space $\left(D_{2}, q\right)$ are flatter than B's. Type A is willing to accept a larger debt reduction for a given change in the price of debt. It, therefore, finds attractive allocations that are not attractive to $\mathrm{B}$.

Type A chooses $\left(D_{2}^{-B}, q\left(D_{2}^{-B}, 1\right)\right)$ while $\mathrm{B}$ chooses its full information allocation $D_{2}^{F I}$. No type has an incentive to deviate unilaterally. But choosing a different allocation than $D_{2}^{F I}$ is costly for A as well. The larger the deviation, the higher the cost for A. Since $D_{2}^{-B}$ is the threshold debt level that allows separation of the types, the equilibrium $e^{*}$ described in proposition 3.1 is the least cost separating equilibrium.

In a separating equilibrium, type A's equilibrium choice of debt is lower than that of the full information solution $\left(D_{2}^{-B}-D_{2}^{F I}<0\right)$. We say that the country is using austerity for signaling purposes. The choice of a lower level of debt improves the debt price schedule, lowering the risk premium associated to each $D_{2}$. Summing up, reducing the amount of debt to the $D_{2}^{-B}$ level has a double effect: it directly improves the risk premium, because it lowers the default probability, and it indirectly affects the perception of the type, which improves the risk premium further. If it were not for the indirect effect, though, type A would not choose to go through with austerity. ${ }^{13}$ Hence, signaling is the key for fiscal policy to tilt toward austerity.

Pooling equilibria. A pooling equilibrium arises if type A does not find it advantageous to reduce the amount of debt in order to obtain the benefits from revealing its type. It consists of an equilibrium debt level $D_{2}^{*}$ and a price of debt $q^{*}\left(D_{2}^{*}, p\right)$, equal for both types. As a result, the lenders cannot distinguish the types from observing their debt choices and their

\footnotetext{
${ }^{13}$ The direct effect is present at the full information problem as well and type A chooses to issue more debt in equilibrium.
} 
best guess is the prior $p$. For example:

Proposition 3.2. A pooling equilibrium at the full information allocation is supported by the belief system $\mu^{*}\left(D_{2}^{F I}\right)=p$ and $\mu^{*}\left(D_{2}\right)=0$ for $D_{2} \neq D_{2}^{F I}$. The price of debt in a pooling equilibrium equals

$$
q^{*}\left(D_{2}^{F I}, p\right)=\beta^{\prime}\left(p\left[1-F\left(D_{2}^{F I}+\underline{c}^{A}\right)\right]+(1-p)\left[1-F\left(D_{2}^{F I}+\underline{c}^{B}\right)\right]\right) .
$$

Proof. Appendix D.

See figure 3, where the price schedule is again represented by the dotted bold line. The off-equilibrium threat that a country will be penalised in its risk premium if it deviates from $D_{2}^{F I}$ might allow a pooling equilibrium to be sustained at the candidate $D_{2}^{F I}$. Any type of sovereign prefers to choose $D_{2}^{F I}$ and be offered the pooling price under these beliefs. Beliefs are admissible because in equilibrium the pooling price satisfies Bayes' rule and offequilibrium they are free to be any $\mu \in[0,1]{ }^{14}$

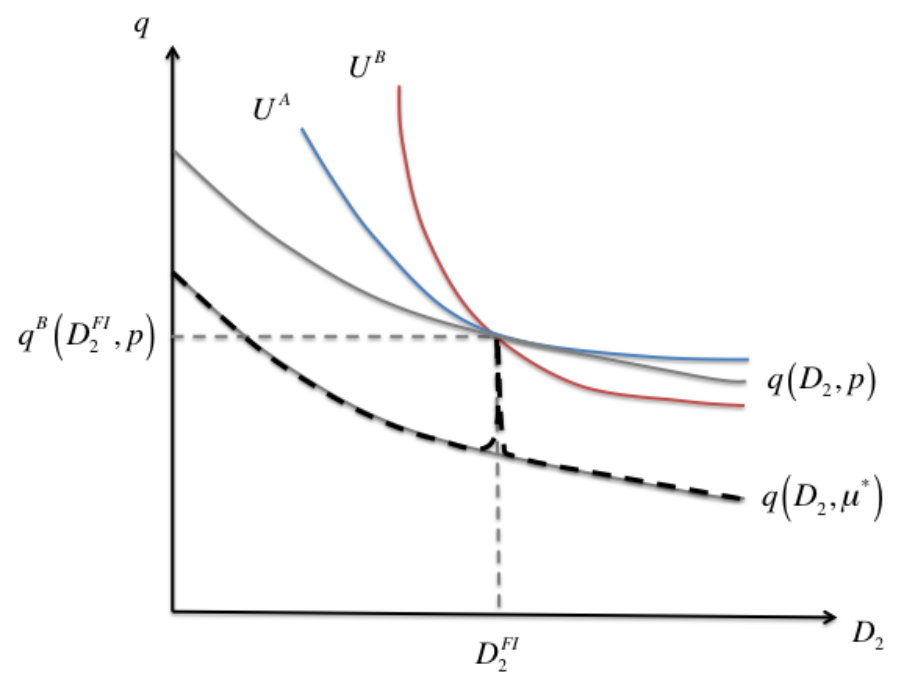

Figure 3: A pooling equilibrium at $D_{2}^{F I}$.

\subsection{Refinements}

A signaling game, like the one presented here, typically admits a multiplicity of equilibria. This is because a large set of off-equilibrium beliefs is consistent with the equilibrium def-

\footnotetext{
${ }^{14}$ They are set to $\mu=0$ in this case.
} 
inition, making it easier to sustain a given equilibrium. In my model, proposition 3.1 and proposition 3.2 are examples of different equilibria that may coexist. To reduce the set of equilibria, I use a refinement of the PBE introduced by Mailath et al. (1993): the undefeated equilibrium (UE).

The UE refinement restricts the set of admissible off-equilibrium beliefs. Beliefs about a deviation to a different allocation are admissible if the probability distribution over types is consistent with such types choosing that allocation in another equilibrium and being weakly better off by doing so. Otherwise, off-equilibrium beliefs are inconsistent. If this offequilibrium consistency requirement restricts beliefs in such a way that they do not sustain a given equilibrium, this equilibrium is defeated and we say that it does not survive the refinement. ${ }^{15}$ An equilibrium is defined to be undefeated if it is not defeated by any other.

Unlike dominance-based refinements, ${ }^{16}$ the UE refinement focuses on the efficiency properties of the equilibrium. The consistency of an off-equilibrium strategy is evaluated on the basis of which type(s) is weakly better off in an alternative equilibrium where this strategy is chosen. In any pooling equilibrium, a sovereign chooses a given $D_{2}$ irrespective of its type. For this equilibrium to be undefeated any type must be better off choosing that allocation compared to deviating to different equilibrium strategy. Thus, the UE privileges the equilibria that are efficient in a Pareto sense.

Proposition 3.3. Applying the UE refinement to the game, equilibria of the separating and the pooling class cannot coexist. For a sufficiently small $p$ there is a unique separating equilibrium where type $A$ chooses $D_{2}^{-B}$, otherwise there are pooling equilibria with $D_{2}>D_{2}^{-B}$.

As stated in the proposition, for $p<\bar{p}$, the unique equilibrium of the problem is $e^{*}$, where $\bar{p}$ is the threshold level of the prior that makes type A indifferent between the signaling allocation $\left(D_{2}^{-B}, q\left(D_{2}^{-B}, 1\right)\right)$ and pooling with type B at $\left(D_{2}^{*}, q\left(D_{2}^{*}, \bar{p}\right)\right)$. The line of proof goes as follows: first, notice that the least costly separating equilibrium $e^{*}$ defeats any other separating equilibrium. All separating equilibria reveal the type of the sovereign but $e^{*}$ does it with the smallest deviation from the full information allocation for type A. Hence, type A is strictly better off at $e^{*}$. This means that off-equilibrium beliefs at $D_{2}^{-B}$ must be $\mu=1$ for any other separating equilibrium but those beliefs do not sustain an equilibrium at $D_{2} \neq D_{2}^{-B}$ because such an equilibrium would be defeated by $e^{*}$. Furthermore, $e^{*}$ defeats any pooling equilibrium if type $\mathrm{A}$ is better off signaling (that is, for $p<\bar{p}$ ). When choosing $D_{2}^{-B}$ gives type A a higher utility, this cannot be ignored off equilibrium in any pooling equilibrium and thus it is inconsistent if A does not realize it would be better off deviating to $D_{2}^{-B}$. The

\footnotetext{
${ }^{15}$ See appendix $\mathrm{E}$ for a formal definition of the UE refinement.

${ }^{16}$ Notably the intuitive criterion by Cho and Kreps (1987) and divinity by Banks and Sobel (1987).
} 
pooling equilibrium is, therefore, defeated. In this case, $e^{*}$ is the unique equilibrium of the model. A formal proof is presented in appendix F.

If $p \geq \bar{p}$ then both types are better off pooling, thus $e^{*}$ is defeated by a pooling equilibrium. The proof is presented in appendix G. The UE refinement allows pooling equilibria to survive. ${ }^{17}$ Pooling $e^{\prime}$ survives if there is no other pooling equilibrium in which both types are better off. Hence, undefeated pooling can be sustained at any allocation in the range $\left[D_{2}^{* A}, D_{2}^{* B}\right]$, where $D_{2}^{* A}$ is the allocation preferred by type A under schedule $q(\cdot, p)$ and $D_{2}^{* B}$ is the one preferred by type B. Pooling equilibria in allocations outside that range are defeated by other pooling equilibria within that range because they are strictly preferred by both types. Within this range moving closer to one type's preferred allocation means moving further from the other; hence, types cannot both be made better off.

Restating the result of proposition 3.3, a separating equilibrium will exist depending on the beliefs about the creditworthiness of a country. A small $p$ reflects a prior that the country is most likely of type B, thus providing large incentives for a type A to signal and separate itself from the uninformed pool. As p becomes larger, ex-ante beliefs of the lenders about creditworthiness are more optimistic, and both types are satisfied foregoing austerity because the potential price benefits of signaling would not be large. Once both types prefer to pool, the least preferred separating equilibrium is defeated and only pooling equilibria exist.

\section{Public information and multiple-periods}

\subsection{Credit rating}

In the model, signaling depends on the belief distribution over types: if lenders believe the sovereign's creditworthiness is most likely high, a country does not gain much from

\footnotetext{
${ }^{17}$ Note that with the 'intuitive criterion' (Cho and Kreps, 1987), the separating equilibrium always eliminates all pooling equilibria and it remains the unique equilibrium in this kind of signaling game with two players and single crossing preferences. According to it, if a deviation from a candidate equilibrium is dominated for one type but not for another, this deviation should not be attributed to the type for which the deviation is dominated. Hence, no pooling equilibrium can dominate the separating equilibrium $e^{*}$ because the single crossing property creates a space between the indifference curves such that any $D_{2}$ to the left of the pooling allocation would be preferred only for type A and not for B. At every such $D_{2}$ beliefs must be such that $\mu=1$ and those off-equilibrium beliefs cannot sustain a candidate pooling equilibrium. The intuitive criterion fixes an equilibrium (e.g. $e^{\prime}$ ) and then restricts the off-equilibrium beliefs that are inconsistent with the dominated choices for each agent based on that equilibrium $e^{\prime}$. Similarly, the UE fixes an equilibrium $e^{\prime}$ but the off-equilibrium beliefs at $D_{2}$ are restricted looking at another equilibrium where this allocation $D_{2}$ is an equilibrium allocation. Restrictions are established based on consistency with the type(s) that would choose $D_{2}$ in the new equilibrium, only if the type(s) are better off than at the fixed equilibrium $e^{\prime}$. So the allocations that dominate the pooling allocation in the intuitive criterion do not exist in the UE because they are not equilibrium strategies of an alternative equilibrium. As a consequence, pooling can survive.
} 
implementing costly austerity to improve the market's perception. Thus, it is useful to explore how changes in the lender's views on creditworthiness affect austerity.

A Credit Rating Agency (CRA) issues sovereign ratings: they are opinions on the credit standing of a country. Credit ratings affect how the public perceives the creditworthiness of the country. I model a sovereign rating as a public signal: $r \in\{\bar{r}, \underline{r}\}$. The rating is imperfectly informative about the country's creditworthiness and the degree of informativeness is captured by a parameter $\rho . \rho \in[0,1]$ is the probability that the CRA detects a type B country and assigns a low rating $\underline{\mathrm{r}}$ : $\operatorname{Prob}(\underline{r} \mid B)$. Country B receives a low rating $\underline{\mathrm{r}}$ with probability $\rho$ and, with probability $1-\rho$, it receives a high rating $\bar{r}$. A type A country always receives a high rating.

Once ratings are assigned, the debt market is segmented into different markets conditional on the rating. A low rating perfectly reveals a $\mathrm{B}$ type and the country rated $\underline{\mathrm{r}}$ is removed from the complementary market $\bar{r}$. Hence, the rating ameliorates the asymmetry of information but does not eliminate it completely. The residual asymmetry of information depends on $\rho .^{18}$ The empirical literature on credit ratings finds robust evidence that the ratings add information on average, measuring the impact that either ratings or new announcements have on the market (Cantor and Packer, 1996; Lee et al., 2010; Pukthuanthong-Le et al., 2007). In addition, some papers note that this impact changes over time (Kiff et al., 2012; De Santis, 2012) and that the explanatory power of the ratings diminishes in times of crisis (Bussiere and Ristiniemi, 2012).

I concentrate my analysis on the $\bar{r}$ category for the remainder of this paper. ${ }^{19}$ Recall from proposition (3.3) that the existence of an equilibrium with 'signaling austerity' depends on the proportion of types $p$. The parameter $\rho$, by modifying the proportion of types in each segmented market, affects the determination of the equilibrium. The posterior $\hat{p}(\rho)$ is:

$$
\hat{p}(\rho, r)=\left\{\begin{array}{lll}
\frac{p}{1-\rho(1-p)} & \text { if } & r=\bar{r} \\
0 & \text { if } & r=\underline{\mathrm{r}} .
\end{array}\right.
$$

If $\rho$ is set to 1 , the CRA provides perfect information about the type of country and the solution is the full information one. If, instead, $\rho=0$, we are in the baseline model with

\footnotetext{
${ }^{18} \rho$ can take on different values, $\in(0,1)$, for a number of reasons that are not explicitly modelled here: for example, a conflict of interest due to the issuer-pays model of rating fees would be represented as a decrease in $\rho$, as we go from an investors-pay to an issuer-pays model. Similarly, either the difficulties of rating an increasingly complex set of products or the lack of attention paid to sovereigns that do not pay for their ratings would also imply a decrease in the parameter $\rho$.

${ }^{19}$ That is because the $\underline{r}$ category reveals a type B country with certainty and, thus, is of no interest for signalling. Alternatively I could model the $\underline{\mathrm{r}}$ rating to be imperfectly informative as well. As the analysis is analogous to that of the $\bar{r}$ category, I opt for this simplified information structure of the signal.
} 
asymmetry of information from the previous section. For values between 0 and 1 , the degree of informativeness affects to a lesser or greater extent the beliefs about the composition of types in the rating category $\bar{r}$ and, thus, the equilibrium debt price of pooling in that category, which equals:

$$
q^{*}\left(D_{2}^{*}, p, \rho \mid \bar{r}\right)=\beta^{\prime}\left[\frac{p}{1-\rho(1-p)}\left(1-F\left(D_{2}^{*}+\underline{c}^{A}\right)\right)+\frac{(1-\rho)(1-p)}{1-\rho(1-p)}\left(1-F\left(D_{2}^{*}+\underline{c}^{B}\right)\right)\right] .
$$

Price is increasing in the prior about creditworthiness - $p$ - and in the ratings capacity to improve the prior with new information - $\rho$. Both $p$ and $\rho$ make the lenders more optimistic about creditworthiness (weighting up the beliefs that they are in front of a type A country and down the beliefs that it is type B instead).

Let $e^{*}$ be the least cost separating equilibrium defined in proposition 3.1 and $\bar{p}$ be the threshold level of the prior that makes type A indifferent between signaling and pooling as described in the previous section.

Proposition 4.1. If the prior $p$ is such that $p<\bar{p}$, there exists a level of informativeness $\rho^{*}$ of the rating so that for all $\rho \geq \rho^{*}$ all equilibria are pooling and for $\rho<\rho^{*}$ the unique equilibrium is $e^{*}$.

Proof. Since the equilibrium for $p$ is $e^{*}$, it follows that type A must prefer $e^{*}$ s equilibrium allocation to the pooling one:

$$
\begin{aligned}
U^{A}\left(D_{2}^{-B}, q\left(D_{2}^{-B}, 1\right)\right) & >U^{A}\left(D_{2}^{*}(p), q\left(D_{2}^{*}(p), p\right)\right) \\
& =U^{A}\left(D_{2}^{*}(\hat{p}), q\left(D_{2}^{*}(\hat{p}), \hat{p}\right)\right) \text { if } \rho=0 .
\end{aligned}
$$

The last line exploits the fact that the two problems without ratings and with ratings that add no information are the same. The left-hand side of (4.2) is independent of $\rho$, while the right-hand side is increasing in $\rho$ because $\left.\frac{\partial \hat{p}}{\partial \rho}\right|_{\vec{r}}>0$. And for $\rho=1-\epsilon$, with $\epsilon$ very small, the right-hand side tends to $U^{A}\left(D_{2}^{F I}, q^{A}\left(D_{2}^{F I}\right)\right)$ and the inequality is reversed. Hence, there must exist a threshold $\rho^{*}$ where the equilibrium shifts from a pooling one to $e^{*}$.

Thus,

Corollary 4.1. A deterioration of ratings informativeness from $\rho \geq \rho^{*}$ to $\rho<\rho^{*}$ makes 'signaling austerity' appear.

A worse posterior $\hat{p}(\rho)$ about the sovereign's ability means that more type B countries are perceived to be in the $\bar{r}$ category and the pooling price is lower for every level of debt. Price schedule $q\left(D_{2}, \hat{p}\right)$ shifts downwards as in the transition from figure 4 a to figure $4 \mathrm{~b}$. 


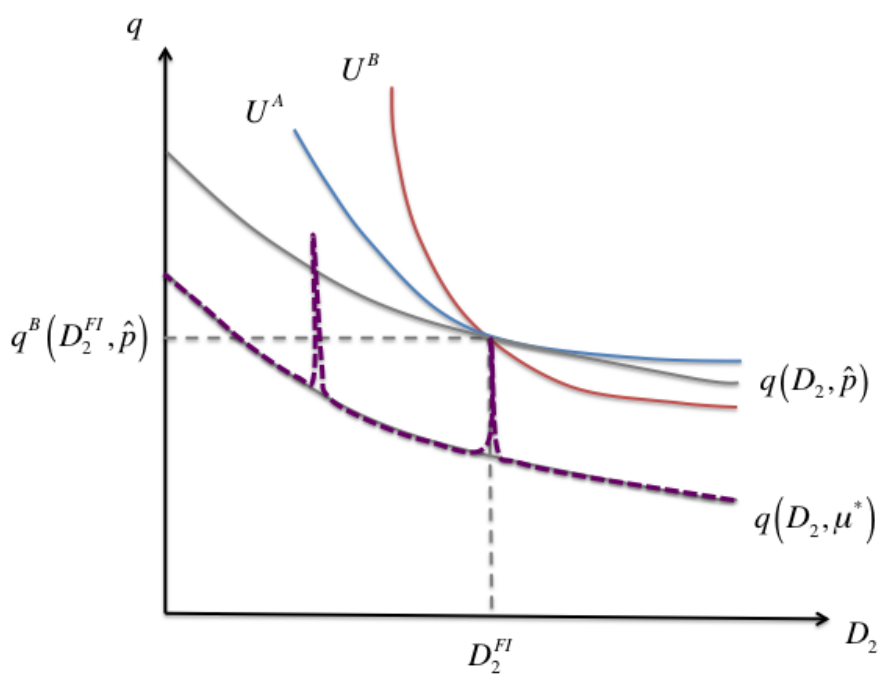

(a) Equilibrium with $\rho \geq \rho^{*}$.

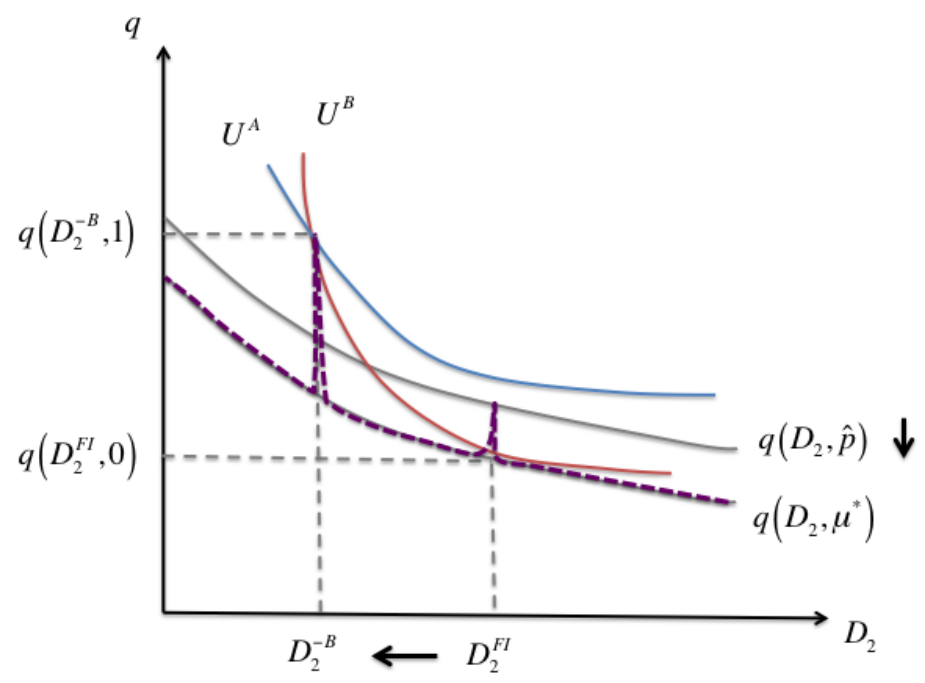

(b) Equilibrium with $\rho<\rho^{*}$.

Figure 4: A change in $\rho$ induces a shift from a pooling (left panel) to a separating (right panel) equilibrium.

If a pooling equilibrium exists, it will be on the new schedule. But, when $\rho<\rho^{*}$, any of the allocations on this schedule is worse off for A than the separating allocation, defeating pooling equilibria. To sum up, a worse perception of the $\bar{r}$-rated category makes it less attractive for A to pool with the others, because the pooling price is low, and revealing the type compensates the cost of austerity.

Think about a situation where the informativeness of the ratings was presumably high, like before the 2008 financial crisis. Ratings are believed to be very informative and the markets take them at face value and react strongly to them. The prediction of the model is that all types of sovereigns would likely find it advantageous to pool at a high debt level. They do not have an incentive to signal through costly austerity in order to overcome the little residual asymmetry of information. However, if the informativeness of the ratings plummets, for instance when the reputation of the rating agencies came into question after the collapse of Lehman Brothers, the equilibrium may shift to a separating equilibrium. In this new scenario, corollary 4.1 tells us to expect 'signaling austerity' as countries benefit from standing out as creditworthy. The effects of signaling will show in the price of debt, which becomes more responsive to the fiscal magnitudes than before. In that way, you can rationalize the surge in austerity in the European core countries in the aftermath of the crisis and the increase in the Euro area sovereign spreads. In the next section, I simulate the model for a number of periods and compare it with the time series data. 


\subsection{A simple multiple-period model with iid shocks to the type}

In this section, I extend the model to multiple periods. There are two cases in which this extension can be done without excessive complications: the case with constant types over time and the case with iid shocks to the type. With constant types, once there is a separating equilibrium, the type is fully revealed. From then onward, each country chooses its optimal amount of debt under perfect information. Signaling, hence, takes place at most once.

With independent shocks to the type, the problem changes in the following way: at the end of period $t$ a new type is drawn, $\underline{c}_{t+1}^{i}$. Then, the income realization $\omega_{t}$ is obtained and the country may default. After a default, there is immediate re-entry in the debt market and the country can borrow again $D_{t+1}$.

The solution to any two consecutive periods $t$ and $t+1$ is the same as that of the previous two-period game. ${ }^{20}$ The reason is that the current realization of the type carries no information about the type in the future and, thanks to the linear preferences and the absence of a dynamic punishment for default, the optimal level of debt is independent from the past stock of debt.

I simulate this economy during $T=28$ to compare it with the last 28 years of data. The parameters of the model are the following: the lender's discount factor is normalized to be $\beta^{\prime}=1$; the sovereign's discount factor is $\beta=0.6$, lower than the lender's to satisfy assumption (A4); the minimum consumption in a type A country is normalized to $\underline{\mathrm{c}}_{A}=0$; while in a type $\mathrm{B}$ country it is higher at $\underline{\mathrm{c}}_{B}=1$. The lower bound of the support of the income distribution is $\underline{\omega}=1$, which satisfies assumption (A2) with equality. The coefficient of the exponential distribution of income $h$ is set to 1 , so the mean income is also $1 . D_{1}-\omega_{1}$ is set to 0 without loss of generality. Finally, the probability of being type $\mathrm{A}$ is set to be $30 \%$.

I assume that the probability that the CRA detects a type B country, $\rho$, is a parameter that becomes known at the beginning of each period. I find the equilibrium of the model for every value of $\rho$ in a grid between $[0,1]$ and calculate the correlation between debt prices and sovereign ratings as a function of $\rho$. I choose the value of $\rho_{t}$ that minimizes the difference between the simulated correlation and the correlation in the data each period.

Figure 5b depicts austerity in the data in the bars, measured as the sum of the primary balance of the government budgets over GDP weighted by the number of countries in each period. ${ }^{21}$ The solid line plots the cross-section correlation between sovereign yields and sovereign ratings for the same sample of countries between 1985 and 2012. The two variables have a negative co-movement: a high correlation between sovereign ratings and yields

\footnotetext{
${ }^{20}$ See appendix $\mathrm{H}$ for a proof.

${ }^{21}$ The sample is described in section 5.1 and can be found in appendix I.
} 


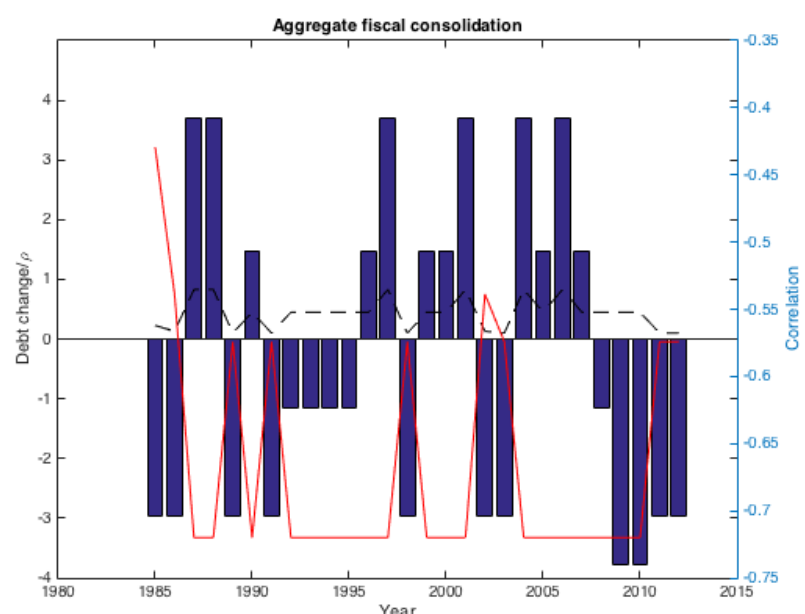

(a) Simulated data.

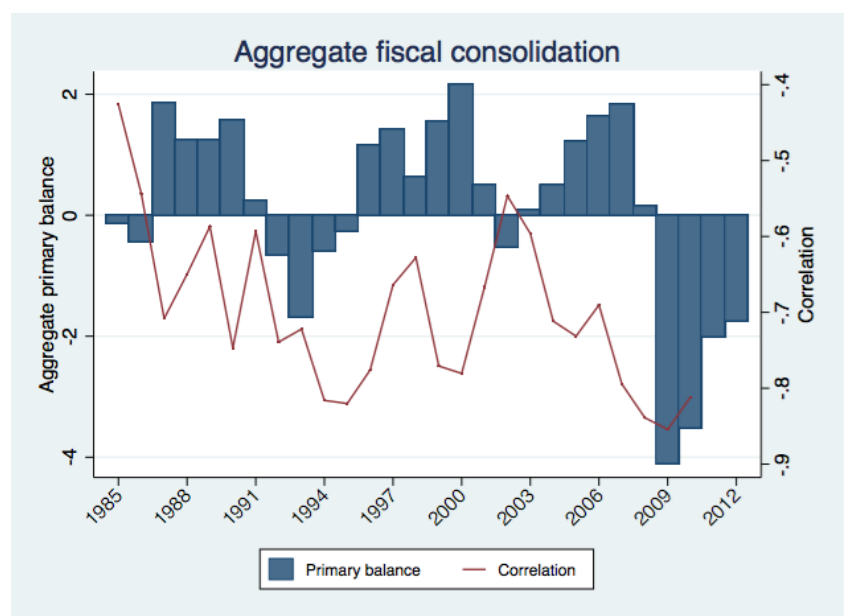

(b) Actual data.

Figure 5: Negative co-movement between correlation and austerity.

happens with little or no austerity while a low correlation is associated with bar spikes in austerity. Figure 5a plots the choice of $\rho_{t}$ (dotted line), the cross-sectional correlation (solid line) and the aggregate debt change implied by the model (bars). I am able to replicate the negative co-movement that we see in the data.

Let us now focus on the evolution of sovereign yields over time. Figure 6 depicts the same bars as before for the aggregate debt change, together with the simulated sovereign bond yields of each country type. A period of separating equilibrium, characterized by austerity, corresponds to the troughs in the bars. At those times, the sovereign yields of the two country types diverge and a positive spread appears between sovereigns in the same rating category. The prediction associated with a pooling equilibrium is the opposite: the debt bars spike and the spread disappears.

The two empirical regularities that emerge in this simple multiple-period model - the negative co-movement between the sovereign yields-ratings correlation and austerity and the changes in yields dispersion with austerity - are used in the empirical analysis in the next section.

\section{$5 \quad$ Empirical analysis}

In this section I go beyond the aggregate data from the previous section and examine individual countries over three decades in a panel regression analysis. A given country's choice of fiscal policy is determined by a number of different variables that the literature has identified (Gali and Perotti, 2003; Favero and Monacelli, 2005; Baldacci et al., 2013). For instance, 


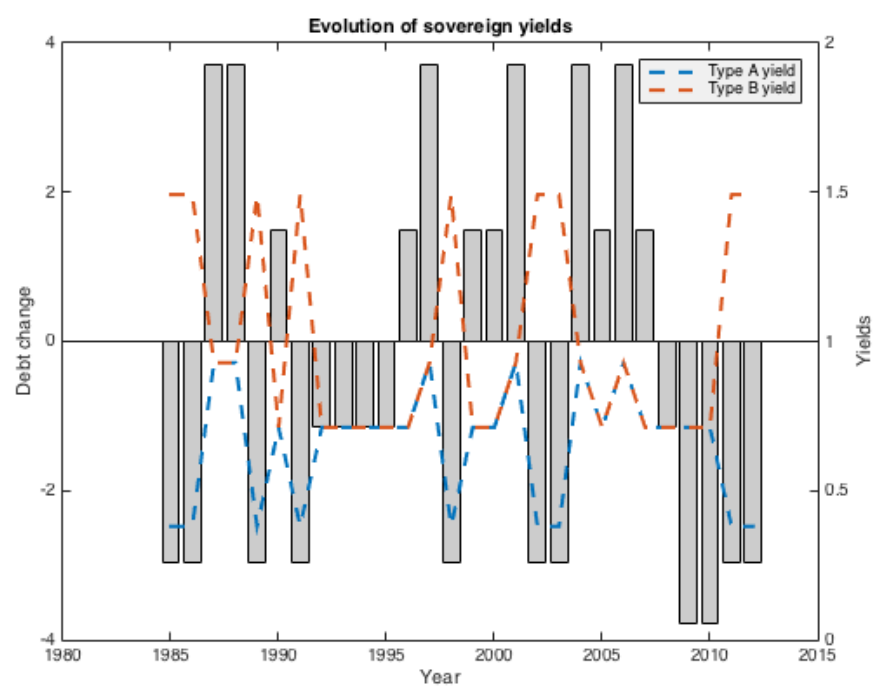

Figure 6: Simulated sovereign yields.

the stock of debt matters for debt sustainability and might affect how much austerity a country engages in. In order to distinguish between how much austerity results from signaling motives, I look at the evolution of austerity that is associated with changes in the incentives to signal, conditional on fundamentals.

Incentives to signal are measured in two ways. The first measure I use is the cross-section correlation between sovereign yields and sovereign ratings in a given period. This variable proxies the market assessment of the ratings' information. According to Corollary 4.1, the less information there is (low $\rho$ ) the more likely is a surge in austerity. This, controlling for other determinants of the fiscal stance. I now explain how the ratings' information is related to the correlation variable in my model. Recall that $\operatorname{Prob}(\underline{\mathrm{r}} \mid B)=\rho$ and $\operatorname{Prob}(\underline{\mathrm{r}} \mid A)=0$ and, in the setup with two ratings, it represents the information that the rating conveys to the market. Since Cantor and Packer (1996), a large body of literature investigates the market impact of credit ratings by regressing the sovereign yields, spreads and other measures of the market value on the sovereign ratings. ${ }^{22}$ Following the literature, I estimate the equation:

$$
\text { Sovereign } \text { Yield }_{i, t}=\rho_{t} \text { Rating }_{i, t}+\epsilon_{i, t} \text {, }
$$

using cross-sectional variation. Hence, $\hat{\rho}_{t}=\operatorname{corr}_{t}\left({\text { Sovereign } \text { Yield }_{t} \text {, Rating }}_{t}\right)$ is an estimate of the changes in public information that the sovereign ratings convey over time. Each year, the correlation reflects the extent to which the sovereign yields charged by the lenders to all sovereigns are explained by the order in which they are placed in the rating scale. A larger

\footnotetext{
${ }^{22}$ Possibly controlling for an array of covariates.
} 
correlation is presumed to mean a high $\rho$ while a lower one implies a low $\rho$. This is what I also find in the simulation of the multiple-period economy in section 4.2 (see figure $5 \mathrm{a}$ ).

An alternative way to identify austerity is to measure if market spreads are dispersing within a given rating category. As shown in figure 6, increased dispersion in yields inside a category is indicative of low informativeness of the ratings and should prompt austerity in the separating equilibrium for that group of countries vis-à-vis the other groups. I look for extreme events in the yields of a sovereign within the yields distribution by rating category in the data: the variable Yield Event $t_{i, k}$ represents the events in country $i$ belonging to the rating category $k$ in year $t$ and takes value 1 if a large change happened and 0 if not. Rating categories are defined more coarsely than the rating grades in order to obtain a larger number of countries in each category. ${ }^{23}$ I define a yield event as extreme when the difference in demeaned log yields between two consecutive years is larger than two standard deviations of the $\log$ yields distribution in that year for that rating category. ${ }^{24}$ Demeaning allows me to remove the time trend in the time series of yields. I use log yields because the interpretation of differences in log yields as percentage changes is useful and more realistic. In appendix J, I present the list of countries experiencing such events. Finally, I aggregate the number of events by rating category at every point in time, excluding those affecting country $j$ itself:

$$
\text { Yield Shocks } s_{j, k, t}=\sum_{i \in k, i \neq j} \text { Yield Events } s_{i, k, t} .
$$

I obtain an indicator variable that takes a higher value when more countries in $j$ 's rating category have price movements at the extremes of the distribution. My empirical strategy then includes these variables that proxy for the willingness to signal - the Correlation or the Yield Shocks - as a regressor $\hat{\rho}_{i t}$ in an equation of the fiscal stance:

$$
\text { Austerity }_{i t}=\alpha+\beta \hat{\rho}_{i t}+\lambda X_{i t}+\xi_{i t}
$$

and let $\hat{\beta}$ capture the effect that changes in these variables have on austerity, beyond what can be explained by other variables included as controls in $X_{i t}$.

Austerity is also proxied by two different variables, depending on the specification, as summarized in table 1 . The first is an indicator variable measuring whether a given country was under a consolidation program. This is determined according to the narrative approach by Devries et al. (2011) and the sample goes from 1978 to 2009 for 17 countries. The

\footnotetext{
${ }^{23}$ The rating categories are: 'Prime' for ratings between AAA and AAA-included, 'Subprime' for ratings between Aa1+ and Aa3- included, 'Investment' between A1+ and Baa3- and 'Non-investment' lower or equal to Ba1+.

${ }^{24}$ This is robust to small changes in the threshold of standard deviations.
} 
second proxy for austerity is a continuous variable for the cyclically adjusted primary balance (CAPB). It is defined as 'general government balance adjusted for nonstructural elements beyond the economic cycle' and data covers 58 countries from 1980 to 2011 and is taken from the WEO database.

Table 1 recaps the main empirical specifications of equation (5.2) for different measures of austerity (consolidation dummy/ CAPB) and the market assessment of the ratings' information (correlation between yields and ratings/ yield shocks). In the table I also report the expected sign of the coefficient according to the implications of the model in section 4.2.

Table 1: Main empirical specifications and expected sign.

\begin{tabular}{|c|c|c|c|}
\hline & \multicolumn{2}{|c|}{$\begin{array}{l}\text { Independent variable: } \\
\text { MARKET ASSESSMENT } \\
\text { RATINGS' INFORMATION }\end{array}$} \\
\hline & & Correlation & Yield Shocks \\
\hline \multirow{2}{*}{$\begin{array}{l}\text { Dependent } \\
\text { variable: } \\
\text { AUSTERITY }\end{array}$} & $\begin{array}{l}\text { Consolidation } \\
\text { dummy }\end{array}$ & negative & positive \\
\hline & $\begin{array}{l}\text { Cyclically adjusted } \\
\text { primary balance }\end{array}$ & negative & positive \\
\hline
\end{tabular}

\subsection{Dataset and description of the variables}

The dataset contains observations at annual frequency for 58 countries over 32 years (19802011). Countries covered principally include OECD countries, as well as a selection of emerging market economies. For a complete list of countries and the range of years covered see appendix I. The economic variables included in the dataset are obtained from the World Economic Outlook (IMF) 2013; the definitions and calculation methods are found in appendix K. These include the following fiscal variables: Net lending/ borrowing, Primary surplus/deficit, CAPB, and Government expenditure. Positive values of these variables except expenditure - mean that the government is saving and negative values indicate that it is borrowing. Hence, increased fiscal austerity is represented by a positive change in savings/ deficit or a negative change in expenditure.

The dataset has been merged with the average yield to maturity in percentage points of long-term government bonds collected by the IMF in its International Financial Statistics and with the data on fiscal consolidations programs by Devries et al. (2011). Finally, I obtained historical data on sovereign ratings by the three biggest rating agencies (Moody's, Fitch and Standard \& Poor's) for my sample of countries. The rating grades (e.g. AAA) were transformed into a numerical variable. I assigned each rating and modulation of the 
rating (outlook/ rating watch) a number on a scale ranging from 0 (default) to 52 (maximum grade). The final Rating variable was obtained taking an annual average of the three ratings (if available). Since each sampled country received an initial sovereign rating at different points in time, the resulting panel is unbalanced. ${ }^{25}$

\subsection{Evidence on 'signaling austerity'}

\subsubsection{Results using the Correlation as the independent variable}

The results presented below correspond to the first column of the specifications in table 1: $\rho_{t}$ is proxied with the correlation variable throughout this section.

First, I use the consolidation episodes as a measure of austerity and I estimate equation (5.2) by probit:

$$
\text { Consolidation }_{i, t}=\alpha+\beta_{c} \operatorname{Corr}_{t}+\lambda X_{i, t-1}+\kappa_{i}+\tau_{t}+\epsilon_{i, t},
$$

where Consolidation $_{i, t}$ is a dummy variable from Devries et al. (2011), that takes the value 1 if the country fiscally consolidates in that year and 0 if it does not; $\operatorname{Corr}_{t}$ is the correlation ${ }^{26}$ variable estimating $\rho_{t}$; and $X_{i, t-1}$ are one-period-lagged control variables (Net lending over GDP, Squared primary surplus, Debt over GDP, Squared debt over GDP, Log fiscal GDP, Log GDP per capita and Growth). The specification includes country and year fixed effects.

The coefficient $\hat{\beta}_{c}=-13.5$ in table 2 is statistically different from zero. A lower correlation variable has a positive effect on the probability that the country is fiscally consolidating, as expected.

I also estimate equation (5.2), letting primary deficit be the measure of austerity, using OLS:

$$
C A P B_{i, t}=\alpha+\beta_{d} \operatorname{Corr}_{t}+\lambda X_{i, t-1}+\kappa_{i}+\epsilon_{i, t}
$$

The link from Corr $_{t}$ to $C A P B_{i, t}$ is hardly endogenous because the correlation is an aggregate measure. One country's austerity, $C A P B_{i, t}$, might affect its yields, which enter the calculation of the correlation. But this variable is a measure of the relation between all yields and all ratings in the sample, hence reverse causality from a given country's austerity $C A P B_{i, t}$ to the global Corr $_{t}$ is unlikely. As can be seen in table 3, the estimated coefficient

\footnotetext{
${ }^{25}$ However, there is no reason to believe that the initial observations for the non-rated countries are not randomly missing.

${ }^{26}$ Correlations are calculated using the Spearman method to preserve the order of the ratings without imposing a linear scale. Results from calculations using the Person correlation are also are available upon request.
} 
Table 2: Panel probit

\begin{tabular}{|c|c|}
\hline & Consolidation dummy \\
\hline Correlation & $\begin{array}{c}-13.54^{* *} \\
(6.558)\end{array}$ \\
\hline Net lending ${ }_{t-1}$ & $\begin{array}{c}-0.295^{* * *} \\
(0.0569)\end{array}$ \\
\hline Primary surplus ${ }_{t-1}^{2}$ & $\begin{array}{l}-0.0156^{*} \\
(0.00879)\end{array}$ \\
\hline Debt $_{t-1}$ & $\begin{array}{l}-0.0129 \\
(0.0280)\end{array}$ \\
\hline $\operatorname{Debt}_{t-1}^{2}$ & $\begin{array}{c}0.000175 \\
(0.000108)\end{array}$ \\
\hline $\log \mathrm{GDP}_{t-1}$ & $\begin{array}{c}3.669^{* *} \\
(1.653)\end{array}$ \\
\hline $\log \operatorname{GDPpc}_{t-1}$ & $\begin{array}{l}-2.859 \\
(2.853)\end{array}$ \\
\hline Growth $_{t-1}$ & $\begin{array}{l}-4.587 \\
(6.625)\end{array}$ \\
\hline Country FE & Yes \\
\hline Time FE & Yes \\
\hline $\mathrm{N}$ & 369 \\
\hline Chi-square & 102.1 \\
\hline Loglikelihood & -137.2 \\
\hline
\end{tabular}

Standard errors in parentheses

${ }^{*} p<0.1,{ }^{* *} p<0.05,{ }^{* * *} p<0.01$
Table 3: OLS with robust standard errors

\begin{tabular}{lc}
\hline \hline & CAPB \\
\hline Correlation & $-1.809^{* *}$ \\
& $(0.805)$ \\
& $0.758^{* * *}$ \\
CAPB $_{t-1}$ & $(0.0461)$
\end{tabular}

Primary surplus ${ }_{t-1}^{2} \quad 0.000165$

(0.00152)

Debt $_{t-1} \quad 0.0575^{* * *}$

$(0.0136)$

$\operatorname{Debt}_{t-1}^{2} \quad-0.000190^{* * *}$

$(0.0000569)$

$\log \mathrm{GDP}_{t-1} \quad-1.055$

(0.919)

$\log \mathrm{GDPpc}_{t-1} \quad 1.267$

Growth $_{t-1}$

1.992

(3.557)

Country FE Yes

Time FE No

\begin{tabular}{lc}
$\mathrm{N}$ & 607 \\
$\mathrm{R}$-square & 0.821 \\
$\mathrm{~F}$ & 51.84 \\
\hline \hline
\end{tabular}

Standard errors in parentheses

${ }^{*} p<0.1,{ }^{* *} p<0.05,{ }^{* * *} p<0.01$ 
$\hat{\beta}_{d}$ is negative and significant. The effect of a 1 point decrease in the correlation implies a 1.8 percentage points increase in cyclically adjusted primary surplus over GDP. Since the correlation is normalized to lie in the interval $[0,1]$, this increase in austerity is difficult to interpret; hence, I use one standard deviation in the distribution of the Corr $_{t}$ variable as a benchmark. Such a change would be responsible for a quarter percentage point change in the structural deficit.

\subsubsection{Robustness}

I performed a series of robustness checks in order to assess whether results are consistent through changes in some measures and specifications. First, I discuss the choice about the measures of austerity. As mentioned in the introduction, there is no clear consensus about the definition of austerity but the one I propose in this paper $^{27}$ requires measuring the discretionary fiscal decisions made by the government. I opted for the narrative approach, in which Devries et al. (2011) identify episodes of fiscal consolidations through "policymakers' intentions and actions as described in contemporaneous policy documents." Their focus is on fiscal actions motivated primarily by deficit reduction as a response to past economic conditions. Hence this measure, by construction, is particularly well-suited for the analysis of discretionary fiscal policy. I also show an alternative proxy for austerity, based on a statistical measure, such as the CAPB. This is the most commonly used aggregate of discretionary fiscal policy. One might wonder, though, whether other fiscal variables are also in line with the results. I present three in table 4. Results are consistent with those in the previous section. The Corr variable co-moves negatively with austerity, represented by larger surpluses and lower expenditures. Coefficients are larger than that of $C A P B$ : a change in Corr of one standard deviation is associated with up to $0.48 \mathrm{pp}$ in austerity.

I then consider additional specifications in order to control for reverse causality. I replaced the $\mathrm{Corr}_{t}$ by the correlation calculated over a random subsample of half the countries $(\mathrm{J})$ in the sample and estimate the following regression for the other countries:

$$
Y_{i, t}=\alpha+\beta \operatorname{Corr}_{t}^{J}+\gamma X_{i, t-1}+\kappa_{i}+\epsilon_{i, t} \forall i \notin J
$$

by OLS. In (5.4) the fiscal position $Y_{i, t}$ cannot affect $\operatorname{Corr}_{t}^{J}$ as a consequence of the computation method because the correlation is calculated for a different subsample. Table 5 shows that the effect found in the previous regressions still holds.

Next, I instrument $\mathrm{Corr}_{t}$ in (5.3) with two instruments: the annual stock prices of the

\footnotetext{
${ }^{27}$ A lower debt choice than that of the full information solution due to the signaling motive (see the definition of 'austerity for signaling purposes' on page 11).
} 
Table 4: OLS with robust standard errors

\begin{tabular}{|c|c|c|c|}
\hline & Net lending & Primary surplus & Expenditure \\
\hline Correlation & $\begin{array}{c}-3.562^{* * *} \\
(0.883)\end{array}$ & $\begin{array}{c}-2.913^{* * *} \\
(0.839)\end{array}$ & $\begin{array}{c}3.260^{* * *} \\
(0.786)\end{array}$ \\
\hline Net lending ${ }_{t-1}$ & $\begin{array}{c}0.740^{* * *} \\
(0.0503)\end{array}$ & & \\
\hline Primary surplus $_{t-1}$ & & $\begin{array}{c}0.723^{* * *} \\
(0.0485)\end{array}$ & \\
\hline Expenditure $_{t-1}$ & & & $\begin{array}{c}0.757^{* * * *} \\
(0.0409)\end{array}$ \\
\hline Primary surplus ${ }_{t-1}^{2}$ & $\begin{array}{c}0.00717 \\
(0.00474)\end{array}$ & $\begin{array}{c}0.00653 \\
(0.00452)\end{array}$ & $\begin{array}{l}-0.00580 \\
(0.00560)\end{array}$ \\
\hline Debt $_{t-1}$ & $\begin{array}{c}0.0893^{* * *} \\
(0.0158)\end{array}$ & $\begin{array}{c}0.112^{* * *} \\
(0.0161)\end{array}$ & $\begin{array}{c}-0.0649 * * * \\
(0.0155)\end{array}$ \\
\hline $\operatorname{Debt}_{t-1}^{2}$ & $\begin{array}{c}-0.000358^{* * *} \\
(0.0000742)\end{array}$ & $\begin{array}{c}-0.000448^{* * *} \\
(0.0000775)\end{array}$ & $\begin{array}{c}0.000267^{* * *} \\
(0.0000704)\end{array}$ \\
\hline $\log \operatorname{GDP}_{t-1}$ & $\begin{array}{l}-0.929 \\
(0.784)\end{array}$ & $\begin{array}{c}-1.818^{* *} \\
(0.826)\end{array}$ & $\begin{array}{c}0.328 \\
(0.777)\end{array}$ \\
\hline $\log \mathrm{GDPpc}_{t-1}$ & $\begin{array}{l}1.825 \\
(2.150)\end{array}$ & $\begin{array}{l}2.712 \\
(2.155)\end{array}$ & $\begin{array}{l}-0.696 \\
(2.199)\end{array}$ \\
\hline Growth $_{t-1}$ & $\begin{array}{c}13.55^{* * *} \\
(4.189)\end{array}$ & $\begin{array}{c}12.28^{* * *} \\
(4.095)\end{array}$ & $\begin{array}{c}-10.59^{* * *} \\
(4.002)\end{array}$ \\
\hline Country FE & Yes & Yes & Yes \\
\hline $\mathrm{N}$ & 741 & 740 & 741 \\
\hline $\mathrm{r} 2$ & 0.764 & 0.730 & 0.960 \\
\hline $\mathrm{F}$ & 38.72 & 32.82 & 862.2 \\
\hline
\end{tabular}

Standard errors in parentheses

${ }^{*} p<0.1,{ }^{* *} p<0.05,{ }^{* * *} p<0.01$ 
Table 5: OLS with robust standard errors

\begin{tabular}{|c|c|c|c|c|c|}
\hline & Consolidation & Net lending & Primary surplus & CAPB & Expenditure \\
\hline Correlation $^{J}$ & $\begin{array}{c}-1.745^{* *} \\
(0.827)\end{array}$ & $\begin{array}{c}-2.566^{* *} \\
(1.041)\end{array}$ & $\begin{array}{c}-3.492^{* * *} \\
(1.007)\end{array}$ & $\begin{array}{c}-1.547^{*} \\
(0.874)\end{array}$ & $\begin{array}{l}1.628^{*} \\
(0.937)\end{array}$ \\
\hline Net lending ${ }_{t-1}$ & & $\begin{array}{c}0.672^{* * *} \\
(0.0693)\end{array}$ & & & \\
\hline Primary surplus $_{t-1}$ & & & $\begin{array}{c}0.572^{* * *} \\
(0.0908)\end{array}$ & & \\
\hline $\mathrm{CAPB}_{t-1}$ & & & & $\begin{array}{c}0.729 * * * \\
(0.0791)\end{array}$ & \\
\hline Expenditure $_{t-1}$ & & & & & $\begin{array}{c}0.797^{* * *} \\
(0.0478)\end{array}$ \\
\hline Primary surplus $s_{t-1}^{2}$ & & $\begin{array}{l}0.000522 \\
(0.00556)\end{array}$ & $\begin{array}{r}-0.000698 \\
(0.00501)\end{array}$ & $\begin{array}{l}-0.00694 \\
(0.00775)\end{array}$ & $\begin{array}{c}0.00208 \\
(0.00610)\end{array}$ \\
\hline Debt $_{t-1}$ & $\begin{array}{c}0.0541^{* *} \\
(0.0215)\end{array}$ & $\begin{array}{l}0.0505^{*} \\
(0.0286)\end{array}$ & $\begin{array}{c}0.0713^{* * *} \\
(0.0266)\end{array}$ & $\begin{array}{c}0.0446 * * \\
(0.0185)\end{array}$ & $\begin{array}{l}-0.0352 \\
(0.0238)\end{array}$ \\
\hline $\operatorname{Debt}_{t-1}^{2}$ & $\begin{array}{c}-0.000102 \\
(0.0000956)\end{array}$ & $\begin{array}{l}-0.000147 \\
(0.000156)\end{array}$ & $\begin{array}{c}-0.000268^{*} \\
(0.000149)\end{array}$ & $\begin{array}{c}-0.000122 \\
(0.0000827)\end{array}$ & $\begin{array}{l}0.0000570 \\
(0.000126)\end{array}$ \\
\hline $\log \operatorname{GDP}_{t-1}$ & $\begin{array}{c}1.460 \\
(1.019)\end{array}$ & $\begin{array}{c}0.316 \\
(0.960)\end{array}$ & $\begin{array}{l}-0.222 \\
(0.979)\end{array}$ & $\begin{array}{l}-0.660 \\
(1.184)\end{array}$ & $\begin{array}{c}-1.673^{* *} \\
(0.838)\end{array}$ \\
\hline $\log \operatorname{GDPpc}_{t-1}$ & $\begin{array}{c}-6.899^{* *} \\
(2.781)\end{array}$ & $\begin{array}{l}-1.976 \\
(2.812)\end{array}$ & $\begin{array}{l}-0.510 \\
(2.816)\end{array}$ & $\begin{array}{l}0.0944 \\
(2.883)\end{array}$ & $\begin{array}{c}5.574^{* *} \\
(2.457)\end{array}$ \\
\hline Growth $_{t-1}$ & $\begin{array}{l}-2.230 \\
(5.927)\end{array}$ & $\begin{array}{c}2.894 \\
(5.141)\end{array}$ & $\begin{array}{c}3.120 \\
(5.269)\end{array}$ & $\begin{array}{c}1.181 \\
(5.891)\end{array}$ & $\begin{array}{l}0.0566 \\
(4.130)\end{array}$ \\
\hline Country FE & Yes & Yes & Yes & Yes & Yes \\
\hline $\mathrm{N}$ & 217 & 465 & 464 & 286 & 465 \\
\hline r2 & & 0.632 & 0.664 & 0.802 & 0.961 \\
\hline $\mathrm{F}$ & & 30.60 & 29.08 & 49.22 & 1123.1 \\
\hline
\end{tabular}

Standard errors in parentheses

${ }^{*} p<0.1,{ }^{* *} p<0.05,{ }^{* * *} p<0.01$ 
company Moody's and the number of negative news about the CRAs. Moody's is one of the big rating agencies and it is quoted in the stock exchange since 1998 (ticker: MCO). I retrieved information on its stock prices (yearly averages) from Bloomberg. I also collected the number of news counts in major distribution newspapers (in English) that contain a negative view of the rating agencies from the LexisNexis database. ${ }^{28}$

The first underlying assumption is that Moody's stock price reflects the ability of the agency to assign informative ratings. The second assumption is that the opinion of experts and the media on the rating agencies' ability is informative. The relevance of these variables

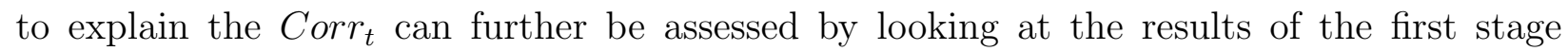
instrumental variables regression in the table in appendix L. On the other hand, neither Moody's stock price nor the critical opinions about the rating agencies should directly affect any given country's willingness to implement austerity; it should only affect this willingness indirectly through the effect they have on the correlation via the signaling channel. In table 6 results are confirmed for several austerity measures and the magnitude of the effect is larger than in the previous estimations.

Further, I also exploit the time-series dimension of the data by substituting Corr $_{t}$ with its one period lag. Since the correlation at $t-1$ is predetermined when looking at it from the current period, it cannot be affected by the austerity that takes place at period $t . X_{i, t-1}$ contains the lagged dependent variables (Net lending, Primary surplus, CAPB, Expenditure), Debt over GDP, Squared debt over GDP, Log fiscal GDP, Log GDP per capita and Growth. In order to deal with possible error autocorrelation, regression (5.3) has been estimated using the Arellano-Bond GMM estimator. ${ }^{29}$ The Corr $_{t-1}$ is instrumented with further lags of the same variable. As reported in table 7, there is no autocorrelation left in the residuals. I also apply the correction for small samples. Results in table 7 confirm the previous ones and are significant. Robust estimators are used to correct for heteroskedasticity.

\subsubsection{Results using the Yield Shocks as the independent variable}

Here I present the results of the estimation corresponding to the specifications in the second column of table 1. The independent variable in this section is the Yield Shocks. The following specification:

$$
Y_{j, k, t}=\alpha+\gamma_{d} \text { Yield Shocks } s_{j, k, t-1}+\lambda X_{j, t-1}+\kappa_{j}+\tau_{t}+u_{j, t}
$$

\footnotetext{
${ }^{28}$ Search key words were 'rating agencies, reputation, accuracy \& criticism', 'rating agencies, credibility \& mistake or error or blame', 'rating agencies, reputation \& regulation' and an example article would be: 'Rating agencies: Capable or culpable?', Euromoney November 2007.

${ }^{29}$ The Arellano-Bond estimator in differences uses first differentiation to eliminate the autocorrelated fixed component of the error term.
} 
Table 6: IV regression results

\begin{tabular}{|c|c|c|c|c|}
\hline & "Net lending & "Primary surplus & CAPB & Expenditure \\
\hline Correlation $_{t-1}$ & $\begin{array}{c}-18.49^{* * *} \\
(3.377)\end{array}$ & $\begin{array}{c}-18.04^{* * *} \\
(3.790)\end{array}$ & $\begin{array}{l}-4.092^{*} \\
(2.418)\end{array}$ & $\begin{array}{c}14.44^{* * *} \\
(2.928)\end{array}$ \\
\hline Net lending $\operatorname{lin}_{t-1}$ & $\begin{array}{c}0.504^{* * *} \\
(0.0387)\end{array}$ & & & \\
\hline Primary surplus ${ }_{t-1}$ & & $\begin{array}{c}0.534^{* * *} \\
(0.0393)\end{array}$ & & \\
\hline $\mathrm{CAPB}_{t-1}$ & & & $\begin{array}{c}0.630 * * * \\
(0.0382)\end{array}$ & \\
\hline Expenditure $_{t-1}$ & & & & $\begin{array}{c}0.542^{* * *} \\
(0.0385)\end{array}$ \\
\hline $\operatorname{Debt}_{t-1}$ & $\begin{array}{c}0.0674^{* * * *} \\
(0.0194)\end{array}$ & $\begin{array}{c}0.110^{* * *} \\
(0.0208)\end{array}$ & $\begin{array}{c}0.0515 * * * \\
(0.0137)\end{array}$ & $\begin{array}{c}-0.0514^{* * *} \\
(0.0170)\end{array}$ \\
\hline $\operatorname{Debt}_{t-1}^{2}$ & $\begin{array}{l}-0.0000956 \\
(0.0000927)\end{array}$ & $\begin{array}{c}-0.000231^{* *} \\
(0.0000957)\end{array}$ & $\begin{array}{l}-0.0000983 \\
(0.0000624)\end{array}$ & $\begin{array}{c}0.0000908 \\
(0.0000806)\end{array}$ \\
\hline $\log \operatorname{GDP}_{t-1}$ & $\begin{array}{l}-0.799 \\
(0.728)\end{array}$ & $\begin{array}{c}-2.040 * * * \\
(0.747)\end{array}$ & $\begin{array}{c}-1.800^{* * *} \\
(0.495)\end{array}$ & $\begin{array}{l}0.0419 \\
(0.632)\end{array}$ \\
\hline $\log \operatorname{GDPpc}_{t-1}$ & $\begin{array}{c}5.418^{* * *} \\
(1.768)\end{array}$ & $\begin{array}{c}7.459^{* * *} \\
(2.227)\end{array}$ & $\begin{array}{c}1.602 \\
(1.377)\end{array}$ & $\begin{array}{l}-0.421 \\
(1.522)\end{array}$ \\
\hline Growth $_{t-1}$ & $\begin{array}{c}4.943 \\
(3.914)\end{array}$ & $\begin{array}{c}1.958 \\
(4.471)\end{array}$ & $\begin{array}{c}2.564 \\
(2.899)\end{array}$ & $\begin{array}{l}-3.265 \\
(3.396)\end{array}$ \\
\hline Country FE & Yes & Yes & Yes & Yes \\
\hline $\mathrm{N}$ & 611 & 541 & 513 & 611 \\
\hline R-square & 0.726 & 0.722 & 0.807 & 0.955 \\
\hline $\mathrm{F}$ & 27.98 & 25.93 & 40.55 & 212.9 \\
\hline
\end{tabular}

Standard errors in parentheses

${ }^{*} p<0.1,{ }^{* *} p<0.05,{ }^{* * *} p<0.01$ 
Table 7: GMM with robust standard errors

\begin{tabular}{|c|c|c|c|c|}
\hline & Net lending & "Primary surplus & $\overline{\mathrm{CAPB}}$ & Expenditure \\
\hline Correlation $_{t-1}$ & $\begin{array}{c}-4.788^{* * *} \\
(1.108)\end{array}$ & $\begin{array}{c}-4.454^{* * *} \\
(1.321)\end{array}$ & $\begin{array}{c}-2.573^{* * *} \\
(0.879)\end{array}$ & $\begin{array}{c}3.789 * * * \\
(0.827)\end{array}$ \\
\hline Net lending ${ }_{t-1}$ & $\begin{array}{c}0.507^{* * * *} \\
(0.101)\end{array}$ & & & \\
\hline Primary surplus $_{t-1}$ & & $\begin{array}{c}0.461^{* * *} \\
(0.134)\end{array}$ & & \\
\hline $\mathrm{CAPB}_{t-1}$ & & & $\begin{array}{c}0.722^{* * *} \\
(0.115)\end{array}$ & \\
\hline Expenditure $_{t-1}$ & & & & $\begin{array}{c}0.648^{* * *} \\
(0.118)\end{array}$ \\
\hline Debt $_{t-1}$ & $\begin{array}{c}0.220 \\
(0.146)\end{array}$ & $\begin{array}{c}0.236^{* * *} \\
(0.0818)\end{array}$ & $\begin{array}{c}0.227^{* * *} \\
(0.0834)\end{array}$ & $\begin{array}{c}-0.285^{* *} \\
(0.128)\end{array}$ \\
\hline $\operatorname{Debt}_{t-1}^{2}$ & $\begin{array}{c}-0.000475 \\
(0.000807)\end{array}$ & $\begin{array}{c}-0.000616 \\
(0.000557)\end{array}$ & $\begin{array}{c}-0.000863 \\
(0.000517)\end{array}$ & $\begin{array}{c}0.00115 \\
(0.000809)\end{array}$ \\
\hline $\log \mathrm{GDP}_{t-1}$ & $\begin{array}{l}-3.842 \\
(6.798)\end{array}$ & $\begin{array}{l}-3.769 \\
(6.656)\end{array}$ & $\begin{array}{c}1.166 \\
(4.499)\end{array}$ & $\begin{array}{c}3.236 \\
(4.879)\end{array}$ \\
\hline $\log \mathrm{GDPpc}_{t-1}$ & $\begin{array}{c}11.55 \\
(19.05)\end{array}$ & $\begin{array}{c}8.179 \\
(17.80)\end{array}$ & $\begin{array}{c}-2.572 \\
(11.63)\end{array}$ & $\begin{array}{c}-9.088 \\
(13.65)\end{array}$ \\
\hline Growth $_{t-1}$ & $\begin{array}{c}25.82^{* * *} \\
(8.767)\end{array}$ & $\begin{array}{c}29.90 * * * \\
(7.788)\end{array}$ & $\begin{array}{c}8.965^{* *} \\
(3.898)\end{array}$ & $\begin{array}{c}-15.47^{*} \\
(8.596)\end{array}$ \\
\hline $\mathrm{N}$ & 821 & 718 & 659 & 821 \\
\hline hansen & 48.61 & 43.15 & 36.46 & 48.79 \\
\hline $\operatorname{AR}(1)$ & 0.00182 & 0.0150 & 0.00634 & 0.00302 \\
\hline $\operatorname{AR}(2)$ & 0.0466 & 0.0457 & 0.115 & 0.112 \\
\hline $\mathrm{F}$ & 26.07 & 21.37 & 26.85 & 26.19 \\
\hline
\end{tabular}

Standard errors in parentheses

${ }^{*} p<0.1,{ }^{* *} p<0.05,{ }^{* * *} p<0.01$ 
estimates how the number of extreme yield events in a rating category affects the fiscal position of the countries in that rating category in the next period.

Table 8: Panel probit

\begin{tabular}{|c|c|}
\hline & Consolidation dummy \\
\hline Yield shocks & $\begin{array}{l}0.389^{*} \\
(0.211)\end{array}$ \\
\hline Net lending $g_{t-1}$ & $\begin{array}{c}-0.306^{* * *} \\
(0.0527)\end{array}$ \\
\hline Primary surplus $_{t-1}^{2}$ & $\begin{array}{c}-0.0112 \\
(0.00907)\end{array}$ \\
\hline Debt $_{t-1}$ & $\begin{array}{c}0.0152 \\
(0.0208)\end{array}$ \\
\hline $\operatorname{Debt}_{t-1}^{2}$ & $\begin{array}{c}0.0000294 \\
(0.000102)\end{array}$ \\
\hline $\log \mathrm{GDP}_{t-1}$ & $\begin{array}{c}2.066 \\
(1.262)\end{array}$ \\
\hline $\log \mathrm{GDPpc}_{t-1}$ & $\begin{array}{c}-7.147^{* *} \\
(3.216)\end{array}$ \\
\hline Growth $_{t-1}$ & $\begin{array}{c}11.91^{* *} \\
(6.070)\end{array}$ \\
\hline Country FE & Yes \\
\hline $\mathrm{N}$ & 335 \\
\hline Chi-square & 83.58 \\
\hline Loglikelihood & -130.8 \\
\hline
\end{tabular}

Note that the definition of Yield Shocks in equation (5.1) does not include country j's own yields events; it contains only information about other countries in the same rating category. Moreover, in order to be more careful, the independent variable is lagged one period. Finally, I also exclude from the estimation those countries experiencing a yield event or a rating change between $t-1$ and $t$. The objective is that the yield shocks are exogenous to the countries' fiscal position $Y_{j, k, t}$ and the effect on austerity comes from the change in information alone. $X_{j, t}$ includes the usual controls and the lagged ratings. ${ }^{30}$

\footnotetext{
${ }^{30}$ In order to control for any other domestic reason that affects the fiscal stance.
} 
Table 9: OLS with robust standard errors

\begin{tabular}{|c|c|c|c|c|}
\hline & Net lending & Primary surplus & $\overline{\mathrm{CAPB}}$ & Expenditure \\
\hline Yield shocks ${ }_{t-1}$ & $\begin{array}{c}0.533^{* * * *} \\
(0.154)\end{array}$ & $\begin{array}{c}0.601^{* * *} \\
(0.166)\end{array}$ & $\begin{array}{c}0.294^{* *} \\
(0.116)\end{array}$ & $\begin{array}{c}-0.247^{* *} \\
(0.118)\end{array}$ \\
\hline Net lending ${ }_{t-1}$ & $\begin{array}{c}0.684^{* * *} \\
(0.0416)\end{array}$ & & & \\
\hline Primary surplus $_{t-1}$ & & $\begin{array}{c}0.738^{* * *} \\
(0.0412)\end{array}$ & & \\
\hline $\mathrm{CAPB}_{t-1}$ & & & $\begin{array}{c}0.725^{* * *} \\
(0.0521)\end{array}$ & \\
\hline Expenditure $_{t-1}$ & & & & $\begin{array}{c}0.762^{* * *} \\
(0.0299)\end{array}$ \\
\hline Debt $_{t-1}$ & $\begin{array}{l}-0.00823 \\
(0.00580)\end{array}$ & $\begin{array}{c}0.0000688 \\
(0.00586)\end{array}$ & $\begin{array}{l}-0.00352 \\
(0.00532)\end{array}$ & $\begin{array}{l}0.0120^{* *} \\
(0.00552)\end{array}$ \\
\hline $\log \mathrm{GDP}_{t-1}$ & $\begin{array}{c}-1.467^{* *} \\
(0.682)\end{array}$ & $\begin{array}{c}-1.981^{* * *} \\
(0.727)\end{array}$ & $\begin{array}{c}-2.267^{* *} \\
(0.963)\end{array}$ & $\begin{array}{l}1.089^{*} \\
(0.640)\end{array}$ \\
\hline $\log \mathrm{GDPpc}_{t-1}$ & $\begin{array}{c}0.714 \\
(1.466)\end{array}$ & $\begin{array}{c}2.430 \\
(1.640)\end{array}$ & $\begin{array}{c}3.098^{*} \\
(1.823)\end{array}$ & $\begin{array}{c}1.329 \\
(1.361)\end{array}$ \\
\hline Growth $_{t-1}$ & $\begin{array}{c}5.198 \\
(3.792)\end{array}$ & $\begin{array}{c}0.501 \\
(4.170)\end{array}$ & $\begin{array}{c}5.121 \\
(6.206)\end{array}$ & $\begin{array}{l}-4.315 \\
(3.534)\end{array}$ \\
\hline Rating $_{t-1}$ & $\begin{array}{c}-0.0837^{* *} \\
(0.0372)\end{array}$ & $\begin{array}{c}-0.0776^{*} \\
(0.0431)\end{array}$ & $\begin{array}{c}-0.0684^{*} \\
(0.0380)\end{array}$ & $\begin{array}{c}0.0418 \\
(0.0341)\end{array}$ \\
\hline Country FE & Yes & Yes & Yes & Yes \\
\hline Time FE & Yes & Yes & Yes & Yes \\
\hline $\mathrm{N}$ & 885 & 772 & 653 & 885 \\
\hline $\mathrm{r} 2$ & 0.838 & 0.831 & 0.870 & 0.978 \\
\hline $\mathrm{F}$ & 45.85 & 40.75 & 99.59 & 783.4 \\
\hline
\end{tabular}

Standard errors in parentheses

${ }^{*} p<0.1,{ }^{* *} p<0.05,{ }^{* * *} p<0.01$ 
The regression results for this specification are presented in tables 8 (independent variable: consolidation dummy) and 9 (independent variables: net lending, primary surplus, CAPB, expenditure). Note that when more countries in your rating category are subject to a yield event, it means a larger number in the variable Yield Shocks $s_{i, k, t}$. Hence, an increase in the explanatory variable is associated with more austerity (an increase in the probability of a fiscal consolidation, $\hat{\gamma}_{c}>0$, or higher values in the primary surplus, $\hat{\gamma}_{d}>0$ ) as expected. This approach confirms the results from previous sections. Experiencing a yield shock in your rating category increases the austerity over GDP on the order of one half percentage points of net borrowing or primary deficit and about one quarter of CAPB. For example, the primary deficit over GDP would go from $3.5 \%$ to $3 \%$.

\subsection{Alternative explanations}

There could be alternative theories explaining the empirical results. I list a selection and discuss them in this section.

First, in order to rule out that austerity is due to criteria of budget sustainability, I control in all above regressions for a set of individual characteristics that the literature identifies as important (Gali and Perotti, 2003; Favero and Monacelli, 2005; Baldacci et al., 2013) and the results all survive.

However, there might still be missing unobservable characteristics. This is a problem insofar the omitted variable is correlated with $\mathrm{Corr}_{t}$. Suppose that we are estimating this regression:

$$
Y_{i, t}=\alpha+\beta \operatorname{Corr}_{t}+\gamma X_{i, t-1}+\kappa_{i}+\epsilon_{i, t}
$$

where in reality $\epsilon_{i, t}=Z_{t}+u_{i, t}$ and $\operatorname{Corr}\left(X_{i, t-1}, Z_{t}\right) \neq 0$. Then, $\operatorname{Corr}\left(X_{i, t-1}, \epsilon_{i, t}\right) \neq 0$ and estimation by OLS would produce biased coefficients. Concerns about omitted variables, e.g. global uncertainty, are addressed by including country and time fixed effects in the last specification (5.5). The effect of changes in information on austerity remains after the omitted variables are controlled for.

There could also be omitted variables that affect only some countries and not others. Particularly problematic is the case when an omitted variable affects the countries in some particular category only. In this case the effects could be confounded with the effects of the yield events operating at the level of the rating category and we would be unsure whether we were capturing the correct effect. For example, think about precautionary savings by countries within a rating category triggered by uncertainty clustered at the category level. Note, though, that the precautionary motive should be homogenous in all countries within 
a given category. But austerity by category shows high dispersion. This indicates that austerity is not implemented by every country, as would be consistent with the precautionary motive, but only by some countries that belong in the category affected by a price change, as consistent with the signaling motive.

The results obtained here could also be attributed to contagion. A shock to a country is transmitted to others, even if they are not directly hit. By the nature of contagion, it cannot be captured by controlling for the fundamentals of the country as I did before. In order to detect contagion among countries, the literature usually relies on price co-movements, thus implying that contagion should matter-of-factly show in the price of debt. Controlling for the country's own lagged log yields and the lagged rating in specification (5.5), as I do in appendix M, I still find an effect of changes in the ratings information content.

One issue that remains is that we cannot predict what each type does because types are not observable (neither in theory nor in the data). But we can work around that in the following ways: one is to use regional sub-samples. I repeat the same regression (5.2) on the sample split by regions (OECD countries, European Union countries, peripheral European countries and emerging market economies). The effect of a decrease in the correlation is qualitatively the same, however, it becomes less significant for the group of peripheral countries and it is not significant for emerging markets (see appendix $\mathrm{N}$ for further details). According to the model, this would be expected if there were a higher proportion of type B countries in these two groups relative to the OECD and EU groups.

Another way is to use a two-stage strategy. In a first stage, I find the proximity to being a 'good type' based on past observable information, where 'good' is defined tautologically as those countries overshooting austerity from that predicted by the fitted regression (5.5). In the second stage I can use the predicted proximity to good type/ austerian to explain the CAPB. It turns out that the more the observable variables predict a country to behave as a 'good' type in a certain year, the higher its out of sample austerity really is (coefficient: 1.201, standard deviation: 0.177$) \cdot{ }^{31}$

\section{Conclusion and policy discussion}

In this paper I show that a sovereign may use fiscal policy as a signal to communicate its ability to repay public debt. In the empirical analysis I find that sovereigns adopt a more austere fiscal policy when the credit ratings are less informative about a country creditworthiness. This result is robust to different empirical strategies, specifications and measures of austerity. The evidence favors the signaling channel over other alternative explanations.

\footnotetext{
${ }^{31}$ The first stage regression uses years 1980 to 2000 and the out of sample prediction 2000 to 2011.
} 
The findings in this paper are relevant for policymakers wishing to implement austerity programs in order to reduce the risk of a sovereign default. For instance, during the recent debt crisis several European countries adopted a common debt ceiling. ${ }^{32}$ In my model this policy is equivalent to setting an exogenous debt limit that is the same for any country type. The introduction of a debt limit may make the optimal choice of debt unfeasible if it is stringent enough. Hence, it triggers a change in the equilibrium that prevails. If the undefeated equilibrium is separating, both countries are worse off because they cannot choose their constrained optimal debt level and the incentive compatibility constraint of the less able country is harder to satisfy. If the undefeated equilibrium is pooling, instead, both types are still worse off, otherwise they could have chosen to pool at that debt level in the unrestricted set-up. In some cases, as in the example in appendix $\mathrm{O}$, the overall riskiness of debt increases. A 'one-size-fits-all' austerity program, such as the Fiscal Compact, may backfire when countries are trying to signal with austerity. ${ }^{33}$

\footnotetext{
${ }^{32}$ The Fiscal Compact introduced the rule of fiscal budget balance in its Article 3 of Title II.

${ }^{33}$ In a different set-up with homogeneous countries and limited commitment, introducing a debt ceiling could instead be useful to overcome the commitment problem.
} 


\section{References}

Acharya, V. V. and Rajan, R. G. Sovereign debt, government myopia, and the financial sector. NBER Working Papers 17542, 2011.

Baldacci, E., Gupta, S., and Mulas-Granados, C. How effective is fiscal policy response in financial crises? In Claessens, S., Kose, M. A., Laeven, L., and Valencia, F., editors, Financial Crises: Causes, Consequences, and Policy Responses, pages 431-457. IMF Publication, 2013.

Banks, J. S. and Sobel, J. Equilibrium selection in signaling games. Econometrica, 55(3): 647-661, 1987.

Bar-Isaac, H. and Shapiro, J. Ratings quality over the business cycle. Journal of Financial Economics, 108(1):62-78, 2013.

Bussiere, M. and Ristiniemi, A. Credit ratings and debt crisis. Banque de France document de travail, 396, 2012.

Cantor, R. and Packer, F. Determinants and impact of sovereign credit ratings. Economic Policy Review, 2(2):37-53, 1996.

Cho, I.-K. and Kreps, D. M. Signaling games and stable equilibria. Quarterly Journal of Economics, 102(2):179-221, 1987.

Cole, H. and Cooley, T. Rating agencies. NBER Working Paper, 19972, 2014.

De Santis, R. The Euro area sovereign debt crisis: safe haven, credit rating agencies and the spread of the fever from Greece, Ireland and Portugal. European Central Bank Working Paper, 1419, 2012.

Dellas, H. and Niepelt, D. Austerity. CESifo Working Paper Series, 5146, 2014.

Devries, P., Guajardo, J., D., L., and Pescatori, A. A new action-based dataset of fiscal consolidation. IMF Working Paper, 11/128, 2011.

Drudi, F. and Prati, A. Signaling fiscal regime sustainability. European Economic Review, 44(2):1897-1930, 2000.

ECB. Analysing government debt sustainability in the euro area. Monthly Bulletin April 2012., 2012.

Favero, C. and Monacelli, T. Fiscal policy rules and regime (in)stability: Evidence from the U.S. IGIER Working Paper, 282, 2005.

Fostel, A., Catao, L., and Ranciere, R. Fiscal discoveries and yield decouplings. Working Paper, 2013.

Gali, J. and Perotti, R. Fiscal policy and monetary integration in Europe. Economic Policy, 18(37):533-572, 2003. 
Holden, S., Natvik, G., and Vigier, A. An equilibrium model of credit rating agencies. Norges Bank Working Paper, 23, 2012.

Josepson, J. and Shapiro, J. Credit ratings and security design. Working Paper, 2014.

Kiff, J., Nowak, S., and Schumacher, L. Are rating agencies powerful? An investigation into the impact and accuracy of sovereign ratings. IMF Working Paper, 12/23, 2012.

Lee, K.-H., Sapriza, H., and Wu, Y. Sovereign debt ratings changes and stock liquidity around the world. Federal Reserve Board mimeo, 2010.

Mailath, G. J., Okuno-Fujiwara, M., and Postlewaite, A. Belief based refinements in signaling games. Journal of Economic Theory, 60(2):241-276, 1993.

Manso, G. Feedback effects of credit ratings. Journal of Financial Economics, 109(2): 535-548, 2013.

Mathis, J., McAndrews, J., and Rochet, J. Rating the raters: Are reputation concerns powerful enough to discipline rating agencies? Journal of Monetary Economics, 56(5): 657-674, 2009.

Opp, C., Opp, M., and Harris, M. Rating agencies in the face of regulation. Journal of Financial Economics, 108(1):46-61, 2013.

Partnoy, F. How and why credit rating agencies are not like other gatekeepers. In Fuchita, Y. and Litan, R., editors, Financial Gatekeepers: Can they protect investors? San Diego Legal Studies Paper 07-46, 2006.

Pukthuanthong-Le, K., Elayan, F., and Rose, L. Equity and debt market responses to sovereign credit ratings announcement. Global Finance Journal, 18(1):47-83, 2007.

Sandleris, G. Sovereign defaults: Information, investment and credit. Journal of International Economics, 76(2):267-275, 2008.

Skreta, V. and Veldkamp, L. Ratings shopping and asset complexity: A theory of ratings inflation. Journal of Monetary Economics, 56(5):678-695, 2009.

Sobel, J. Signaling games. Encyclopedia of Complexity and Systems Science, pages 81258139, 2009.

Spence, M. Job market signaling. The Quarterly Journal of Economics, 87(3):355-374, 1973.

StLouisFED. An application of conventional sovereign debt sustainability analysis to the current debt crises. Federal Reserve Bank of St. Louis REVIEW May/June 2012, 2012.

White, L. J. The credit rating agencies. Journal of Economic Perspectives, 24(2):211-226, 2010. 


\section{APPENDIX}

\section{A The single crossing property}

The single crossing condition of indifference curves is defined as a ranking of the slopes of the indifference curves $U^{i}\left(D_{2}, q\right)$ such that $\Delta^{A}\left(D_{2}, q\right)<\Delta^{B}\left(D_{2}, q\right)$ for all $D_{2}, q$ in the relevant range, where $\Delta^{i}\left(D_{2}, q\right):=-\frac{\frac{\partial U^{i}\left(D_{2}, q\right)}{\partial D_{2}}}{\frac{\partial U^{i}\left(D_{2}, q\right)}{\partial q}}$. Let us show that the indifference curves of country type A are flatter than those of country type B. First, let us define the relevant range of $D_{2}$. Let $\underline{D}_{2}^{i}$ be the threshold level of debt that satisfies constraint (2.5) for $t=1$ for each type:

$$
\underline{D}_{2}^{i}=\frac{\underline{c}^{i}-\omega_{1}+D_{1}}{\beta^{\prime}\left[1-F\left(\underline{D}_{2}^{i}+\underline{c}^{i}\right)\right]} .
$$

Substituting $F(\cdot)$ for its functional form, we obtain:

$$
\underline{D}_{2}^{i}=\frac{\underline{c}^{i}-\omega_{1}+D_{1}}{\beta^{\prime}} e^{h\left(\underline{c}^{i}-\underline{\omega}\right)} e^{h \underline{D}_{2}^{i}} .
$$

Since $e^{h \underline{D}_{2}^{i}}$ is bounded between 0 and $1, \underline{D}_{2}^{i}>0$. Moreover, since $\underline{c}^{A}<\underline{c}^{B}, \underline{D}_{2}^{A}<\underline{D}_{2}^{B}$. Thus, the relevant range of $D_{2}$ is $\left[\underline{D}_{2}^{B}, \infty\right)$.

Next, let us compute $\Delta^{i}\left(D_{2}, q\right)$ for each type. Total differentiation of equation (2.6) gives:

$$
\begin{aligned}
0 & =D_{2} \cdot d q+ \\
& +\left[q+\beta F^{\prime}\left(D_{2}+\underline{c}^{i}\right) \underline{c}^{i}-\beta F^{\prime}\left(D_{2}+\underline{c}^{i}\right)\left(D_{2}+\underline{c}^{i}\right)+\beta F^{\prime}\left(D_{2}+\underline{c}^{i}\right) D_{2}-\beta\left(1-F\left(D_{2}+\underline{c}^{i}\right)\right)\right] \cdot d D_{2}
\end{aligned}
$$

and, simplifying,

$$
0=D_{2} \cdot d q+\left[q-\beta\left(1-F\left(D_{2}+\underline{c}^{i}\right)\right)\right] \cdot d D_{2}
$$

Therefore, $\Delta^{i}\left(D_{2}, q\right)=-\frac{q-\beta\left(1-F\left(D_{2}+\underline{c}^{i}\right)\right)}{D_{2}}$ and $\Delta^{A}\left(D_{2}, q\right)<\Delta^{B}\left(D_{2}, q\right)$ if $\Delta^{i}\left(D_{2}, q\right)<0$, which is the case for all $D_{2} \in\left[\underline{D}_{2}^{B}, 0\right)$ given assumption (A4).

\section{B Full information optimal allocation}

Let us show that the optimal level of debt under full information $D_{2}^{F I}$ is a local maximum. Differentiating the FOC (3.2) with respect to $D_{2}$ and rearranging gives:

$$
F^{\prime \prime}\left(D_{2}+\underline{c}^{i}\right)\left[-\beta^{\prime} D_{2}-\beta^{\prime} \frac{F^{\prime}\left(D_{2}+\underline{c}^{i}\right)}{F^{\prime \prime}\left(D_{2}+\underline{c}^{i}\right)}+\left(\beta^{\prime}-\beta\right) h^{-1}\right] \text {. }
$$


In order to sign the previous expression, substitute $F(\omega)$ for its functional form $1-e^{-h \omega-\underline{\omega}}$. $F^{\prime \prime}(\omega)<0$ and for equation (B.1) to be negative it must be that

$$
-\beta^{\prime} D_{2}-\beta^{\prime} \frac{F^{\prime}\left(D_{2}+\underline{c}^{i}\right)}{F^{\prime \prime}\left(D_{2}+\underline{c}^{i}\right)}+\left(\beta^{\prime}-\beta\right) h^{-1}>0,
$$

therefore,

$$
D_{2}<\frac{\beta^{\prime}-\beta}{\beta^{\prime} h}+\frac{1}{h}
$$

The derivative of the FOC is negative when (B.2) holds. Since $D_{2}^{F I}=\frac{\beta^{\prime}-\beta}{\beta^{\prime} h}$ and $h>0$, the expression (B.1) is negative at $D_{2}^{F I}$ and $D_{2}^{F I}$ is a local maximum.

\section{Separating equilibrium}

We show that the allocation $\left[\left(D_{2}^{-B}, q\left(D_{2}^{-B}, 1\right)\right),\left(D_{2}^{F I}, q\left(D_{2}^{F I}, 0\right)\right)\right]$, along with beliefs $\mu^{*}\left(D_{2}^{-B}\right)=$ 1 , and $\mu^{*}\left(D_{2}\right)=0$ for $D_{2} \neq D_{2}^{-B}$, constitutes a separating equilibrium outcome. Recall that $D_{2}^{-B}$ is the debt level that satisfies type B's incentive compatibility constraint (3.5) with equality:

$$
U^{B}\left(D_{2}^{-B}, q\left(D_{2}^{-B}, 1\right)\right)=U^{B}\left(D_{2}^{F I}, q\left(D_{2}^{F I}, 0\right)\right)
$$

Let $D_{2}^{A, B}$ be the debt level most preferred by type A under the price schedule $q\left(D_{2}, 0\right)$.

Now let us define $\mathbf{q}_{i}\left(D_{2}, U\right)$ as the indirect function that gives the price of debt necessary to keep type $i$ 's utility constant at $U$ for a given debt $D_{2} . \mathbf{q}_{i}(\cdot)$ is continuous and one-to-one. If $\bar{U}=U^{B}\left(D_{2}^{F I}, q\left(D_{2}^{F I}, 0\right)\right)$ is the utility level of country B in the full information equilibrium, $\mathbf{q}_{B}\left(D_{2}^{F I}, \bar{U}\right)$ is equal to the price $q\left(D_{2}^{F I}, 0\right)$ by definition. On the other hand, we know that $q\left(D_{2}, 0\right)<q\left(D_{2}, 1\right) \quad \forall D_{2}$ and, in particular, for $D_{2}^{F I}$. Therefore,

$$
\mathbf{q}_{B}\left(D_{2}^{F I}, \bar{U}\right)=q\left(D_{2}^{F I}, 0\right)<q\left(D_{2}^{F I}, 1\right)
$$

Hence, $\mathbf{q}_{B}\left(D_{2}^{F I}, \bar{U}\right)$ lies below $q\left(D_{2}^{F I}, 1\right)$. Now let us check how these two functions behave to the left of $D_{2}^{F I}$ :

$$
q\left(\underline{D}_{2}^{B}, 1\right)=\beta^{\prime}\left[1-F\left(\underline{D}_{2}^{B}+\underline{c}^{A}\right)\right]
$$

is positive and bounded and $\lim _{D_{2} \rightarrow \underline{D}_{2}^{B}} \mathbf{q}_{B}\left(D_{2}, \bar{U}\right)=+\infty$.

In the limit $\mathbf{q}_{B}\left(D_{2}, \bar{U}\right)$ is above $q\left(D_{2}, 1\right)$. Since $q(., 1)$ is continuous in $D_{2}$ and so is $\mathbf{q}_{B}\left(D_{2}, \bar{U}\right)$ for $D_{2} \neq 0, \mathbf{q}_{B}\left(D_{2}, \bar{U}\right)$ and $q\left(D_{2}, 1\right)$ must intersect at some $D_{2}$ between $\underline{D}_{2}^{B}$ and $D_{2}^{F I}$. Hence, there exists a $D_{2}^{-B} \in\left[\underline{D}_{2}^{B}, D_{2}^{F I}\right]$ such that the isoutility curve of B going through $\left(D_{2}^{F I}, q\left(D_{2}^{F I}, 0\right)\right)$ crosses the price schedule $q\left(D_{2}, 1\right)$.

It remains to be proven that type A prefers choosing $D_{2}^{-B}$ and having the price of debt $q\left(D_{2}^{-B}, 1\right)$ to choosing $D_{2}^{A, B}$ and having the price $q\left(D_{2}^{A, B}, 0\right)$. First, note that the full information allocation is optimal for type $\mathrm{B}$, hence, it is its highest isoutility curve under 
the $q\left(D_{2}, 0\right)$ schedule. It follows that the price schedule $q\left(D_{2}, 0\right)$ must lie below B's isoutility curve going through the full information allocation for all $D_{2} \neq D_{2}^{F I}$. So, in order to satisfy the tangency condition of $D_{2}^{A, B}$ for type A, the allocation $\left(D_{2}^{A, B}, q\left(D_{2}^{A, B}, 0\right)\right)$ must be below the isoutility curve of $\mathrm{B}$ going through $\left(D_{2}^{F I}, q\left(D_{2}^{F I}, 0\right)\right)$. And, given that the isoutility curves of $\mathrm{A}$ in $\left(D_{2}, q\right)$ are steeper than those of $\mathrm{B}$ for any $D_{2}$, the two can only cross to the right of $D_{2}^{A, B}$. Since they cannot cross to the left of $D_{2}^{A, B}$ it is impossible that $\left(D_{2}^{A, B}, q\left(D_{2}^{A, B}, 0\right)\right)$ is on a higher isoutility curve of $\mathrm{A}$ than $\left(D_{2}^{-B}, q\left(D_{2}^{-B}, 1\right)\right)$. Otherwise, it would be preferred by $\mathrm{B}$ as well and that is a contradiction to (C.1).

\section{Pooling equilibrium at $D_{2}^{F I}$}

In order to show that there can be a pooling equilibrium at the full information debt level, note that B's utility level pooling at $\left(D_{2}^{F I}, q^{*}\left(D_{2}^{F I}, p\right)\right)$ must be higher than the full information allocation $\left(D_{2}^{F I}, q^{*}\left(D_{2}^{F I}, 0\right)\right)$ because the debt level is the same but the price is better. Since $\mu^{*}\left(D_{2}\right)=0$ for any $D_{2} \neq D_{2}^{F I}$, type B's optimal choice of $D_{2}^{*}(B)$ is $D_{2}^{F I}$. At the same time, A's utility at $\left(D_{2}^{F I}, q^{*}\left(D_{2}^{F I}, p\right)\right)$ also needs to be higher than at its preferred allocation under the $q\left(D_{2}, 0\right)$ schedule, $\left(D_{2}^{A, B}, q\left(D_{2}^{A, B}, 0\right)\right)$. By contradiction, for $\left(D_{2}^{A, B}, q\left(D_{2}^{A, B}, 0\right)\right)$ to be preferred, $U^{A}$ going through it must cross $q(\cdot, p)$ at some point between $D_{2}^{A, B}$ and $D_{2}^{F I}$. At $D_{2}^{A, B}, q\left(D_{2}^{A, B}, p\right)>q\left(D_{2}^{A, B}, 0\right)$ and, as $D_{2} \rightarrow \infty$, the $\lim _{D_{2} \rightarrow \infty} q\left(D_{2}, p\right)>0$ and the indifference curve going through $\left(D_{2}^{A, B}, q\left(D_{2}^{A, B}, 0\right)\right)$ goes to 0 . Continuity and monotonicity of $q\left(D_{2}, p\right)$ is straightforward and of the indifference curve has been shown in appendix B. Hence, they cannot cross to the right of $D_{2}^{A, B}$, and $D_{2}^{F I}$ is type A's optimal choice. To sum up, $D_{2}^{F I}$ is the optimal choice of both $\mathrm{A}$ and $\mathrm{B}$ given the system of beliefs and, therefore, by Bayes' rule, $\mu=p$ at $D_{2}^{F I}$.

\section{E Definition of the Undefeated Equilibrium refinement}

Let $e^{*}$ and $e^{\prime}$ be two equilibria of the game and $\left\{\left(D_{2}^{*}(i), q^{*} ; \mu^{*}(\cdot)\right)\right\}_{i \in\{A, B\}}$ and $\left\{\left(D_{2}^{\prime}(i), q^{\prime} ; \mu^{\prime}(\cdot)\right)\right\}_{i \in\{A, B\}}$ its respective outcomes. If:

1. $D_{2}^{\prime}$ is a non-equilibrium outcome in $e^{*}$.

2. $\Theta=\{\{A\},\{B\},\{A, B\},\{\emptyset\}\}$ is the set of types that choose strategy $D_{2}^{\prime}$ in $e^{\prime}$.

3. Denoting $U^{i}(e)$ the utility of type $i$ under equilibrium $e$ :

$$
U^{i}\left(e^{\prime}\right) \geq U^{i}(e) \forall i \in \Theta,
$$

with the inequality being strict for at least one $i \in \Theta$.

4. The off-equilibrium beliefs after observing $D_{2}^{\prime}$ in $e^{*}, \mu^{*}\left(D_{2}^{\prime}\right)$, are positive for the type(s) with a strict inequality and zero for the type(s) not belonging to $\Theta$,

then, whenever $\mu^{*}\left(D_{2}^{\prime}\right)$ do not support $e^{*}, e^{*}$ is defeated by $e^{\prime}$. 


\section{F Selection of the separating equilibrium $e^{*}$}

For $e^{*}$ to be the unique equilibrium it must be that: a) $e^{*}$ is undefeated and b) it defeats all other equilibria.

a) $e^{*}$ is defeated if there is an equilibrium $e^{\prime}$ whose $\mu^{\prime}$ at $D_{2}^{\prime}$ is not consistent with $e^{*}$. Note that this can only happen:

- To the right of $D_{2}^{-B}$ if $\forall D_{2} \in\left[\underline{D}_{2}^{B}, D_{2}^{-B}\right] \quad q\left(D_{2}, \mu\right)>q\left(D_{2}, 1\right)$, which is impossible according to the definition of $\mathrm{PBE}$.

- To the left of $D_{2}^{-B}$ any possible equilibria are of the pooling type. Hence, equilibrium beliefs are $q\left(D_{2}, \mu\right)=q\left(D_{2}, p\right)$ and $q\left(D_{2}, p\right)$ needs to be above A's isoutility curve going through $\left(D_{2}^{-B}, q\left(D_{2}^{-B}, 1\right)\right)$.

Thus, $q\left(D_{2}, p\right)<\mathbf{q}\left(D_{2}, \bar{U}^{A}\right)$, where $\bar{U}^{A}=U^{A}\left(D_{2}^{-B}, q\left(D_{2}^{-B}, 1\right)\right)$, is the condition for $e^{*}$ to survive. ${ }^{34}$ The condition holds for a sufficiently low $p$ :

$$
p<1+\frac{\bar{U}^{A}-\omega_{1}+D_{1}+\left(2 \beta-\beta^{\prime}\right)\left(1-F\left(D_{2}+\underline{c}_{A}\right)\right)-\beta\left(1+\underline{c}_{A}+D_{2}+h^{-1}\right)}{\beta^{\prime} D_{2}\left(F\left(D_{2}+\underline{c}_{B}\right)-F\left(D_{2}+\underline{c}_{A}\right)\right)} .
$$

For example, for $\beta^{\prime}=1, \beta=0.6, \underline{\mathrm{c}}_{A}=0, \underline{\mathrm{c}}_{B}=1, h=1$ and $D_{1}-\omega_{1}=0$, any $p<1$ would work.

b) Now, take $e^{*}$ that is undefeated. This means that $U^{i}\left(e^{*}\right) \geq U^{i}\left(e^{\prime}\right) \forall i$, with strict inequality for at least one $i$, for any other equilibrium $e^{\prime}$. On the other hand, off-equilibrium beliefs in equilibrium $e^{\prime}$ must be $\mu^{\prime}\left(D_{2}\right) \neq 1 \forall D_{2} \neq D_{2}^{\prime}$ in order to be able to sustain $e^{\prime}$. But, since $\Theta=\{A\}$ for $D_{2}^{-B}$ in $e^{*}$ and $U^{A}\left(e^{*}\right)>U^{A}\left(e^{\prime}\right), \mu^{\prime}\left(D_{2}^{-B}\right)=1$ and any $e^{\prime}$ is defeated by $e^{*}$.

\section{G Selection of the pooling equilibria}

Let us show that a pooling equilibrium $e^{\prime}$ can defeat the least cost separating equilibrium $e^{*}$. $e^{\prime}$ will defeat $e^{*}$ if $U^{A}\left(e^{\prime}\right) \geq U^{A}\left(e^{*}\right)$ and $U^{B}\left(e^{\prime}\right)>U^{B}\left(e^{*}\right)$. $D_{2}^{\prime}$ is not an equilibrium strategy for $\mathrm{A}$ in $e^{*}$ but both types choose $D_{2}^{\prime}$ in $e^{\prime}$, hence $\Theta=\{A, B\}$. Off-equilibrium beliefs about the type(s) that choose $D_{2}^{\prime}$ in $e^{*}$ need to be positive for both $\mathrm{A}$ and $\mathrm{B}$. Hence,

$$
\mu^{*}\left(D_{2}\right)= \begin{cases}p & \text { if } D_{2}^{\prime} \\ 1 & \text { if } D_{2}^{-B} \\ 0 & \text { otherwise. }\end{cases}
$$

Condition $U^{B}\left(e^{\prime}\right)>U^{B}\left(e^{*}\right)$, i.e. $U^{B}\left(D_{2}^{F I}, q^{*}\left(D_{2}^{F I}, p\right)\right)>U^{B}\left(D_{2}^{F I}, q^{*}\left(D_{2}^{F I}, 0\right)\right)$, is clearly true. And for its A counterpart, $U^{A}\left(D_{2}^{F I}, q^{*}\left(D_{2}^{F I}, p\right)\right) \geq U^{A}\left(\left(D_{2}^{-B}, q^{*}\left(D_{2}^{-B}, 1\right)\right)\right.$, it suffices to

\footnotetext{
${ }^{34} \mathbf{q}(\cdot)$ has been defined as the function that maps $\left(D_{2}, \bar{U}^{A}\right)$ to $q: \mathbb{R} \times \mathbb{R} \rightarrow \mathbb{R}_{+}$.
} 
choose a $p$ that is close enough to 1 . Take, for example, $1-\epsilon$, where $\epsilon$ is very small. Note that

$$
U^{A}\left(D_{2}^{F I}, q^{*}\left(D_{2}^{F I}, p\right)\right)=p\left[U^{A}\left(D_{2}^{F I}, q^{*}\left(D_{2}^{F I}, 1\right)\right)\right]+(1-p)\left[U^{A}\left(D_{2}^{F I}, q^{*}\left(D_{2}^{F I}, 0\right)\right)\right]
$$

and that

$$
U^{A}\left(D_{2}^{F I}, q^{*}\left(D_{2}^{F I}, 1\right)\right)>U^{A}\left(D_{2}^{-B}, q^{*}\left(D_{2}^{-B}, 1\right)\right)
$$

because it is the full information solution. Thus, using $p=1-\epsilon$,

$$
\begin{aligned}
U^{A}\left(D_{2}^{F I}, q^{*}\left(D_{2}^{F I}, p\right)\right) & =(1-\epsilon)\left[U^{A}\left(D_{2}^{F I}, q^{*}\left(D_{2}^{F I}, 1\right)\right)\right]+\epsilon\left[U^{A}\left(D_{2}^{F I}, q^{*}\left(D_{2}^{F I}, 0\right)\right)\right] \\
& >U^{A}\left(\left(D_{2}^{-B}, q^{*}\left(D_{2}^{-B}, 1\right)\right)\right.
\end{aligned}
$$

\section{H Multiple-period model}

Let us show that the multiple period problem with iid shocks to the type is the same as the repetition of the two-period model. We will construct our model backwards, starting from the two period version of the model. Recall the two-period sovereign problem. When $D_{2}$ is chosen the borrower knows his type $\underline{c}_{2}^{i}$. By analogy, we will keep this important timing assumption. With the aim of writing the general multi-period problem, we write the twoperiod problem emphasizing the relevant states and eliminating the time subscript. Future choices are indicated with prime. Moreover, we write the generalized version of it with an arbitrary initial level of debt $D$ and endowment $\omega$ and allowing the possibility of default. Let

$$
u(D, \omega, \underline{c}):=\max \{\underline{c}, \omega-D\}
$$

be the flow value in each period considering the default choice and assuming that the choice of default occurs before issuing the new debt.

$$
\max _{D^{\prime}, c} \quad c+\beta \int_{\underline{\omega}}^{\infty} u\left(D^{\prime}, \omega^{\prime}, \underline{c}^{\prime}\right) f\left(\omega^{\prime}\right) d \omega^{\prime}
$$

subject to

$$
c=\left\{\begin{array}{l}
\omega-D+q\left(D^{\prime}, \mu\left(D^{\prime}\right)\right) D^{\prime} \quad \text { if } \omega>D+\underline{c}, \\
\underline{c}+q\left(D^{\prime}, \mu\left(D^{\prime}\right)\right) D^{\prime} \quad \text { otherwise }
\end{array}\right.
$$

The borrower takes as given the price schedule and the belief schedule that generates it. For all $D^{\prime}$ and $\mu\left(D^{\prime}\right)$ consistent with lender optimality and competition in the lending market, we have: $q\left(D^{\prime}, \mu\left(D^{\prime}\right)\right)=\beta^{\prime}\left[\mu\left(D^{\prime}\right)\left(1-F\left(D^{\prime}+\underline{c}^{A}\right)\right)+\left(1-\mu\left(D^{\prime}\right)\right)\left(1-F\left(D^{\prime}+\underline{c}^{B}\right)\right)\right]$. In the baseline version of the model in the main text, we assumed fixed types and no default in the first period.

Before moving to three or more periods note that - thanks to the linearity of preferences, 
the previous problem can be rewritten as follows:

$$
\begin{aligned}
& \max _{D^{\prime}} u(D, \omega, \underline{c})+q\left(D^{\prime}, \mu\left(D^{\prime}\right)\right) D^{\prime}+\beta \int_{\underline{\omega}}^{\infty} u\left(D^{\prime}, \omega^{\prime}, \underline{c}^{\prime}\right) f\left(\omega^{\prime}\right) d \omega^{\prime} \\
= & u(D, \omega, \underline{c})+W_{1}\left(\underline{c}^{\prime}, \mu\right),
\end{aligned}
$$

where

$$
W_{1}\left(\underline{c}^{\prime}, \mu\right):=\max _{D^{\prime}} q\left(D^{\prime}, \mu\left(D^{\prime}\right)\right) D^{\prime}+\beta \int_{\underline{\omega}}^{\infty} u\left(D^{\prime}, \omega^{\prime}, \underline{c}^{\prime}\right) f\left(\omega^{\prime}\right) d \omega^{\prime} .
$$

This formulation emphasizes an important stationary property of our model with linear preferences: the decision of future debt is only function of the type the borrower knows at the moment of re-payment. In particular, it does not depend on the initial outstanding debt or the previous type of the borrower. The simple default condition arises from the assumption that there is no dynamic punishment for default. We now move to three periods. We assume that types $c_{t}^{i}$ are drawn independently across time, with support $\{A, B\}$ and probability $p$ and $1-p$, respectively. We can consider the previous two-period model as the last two periods of a three-period model. Assuming the lender beliefs schedule - and hence the price schedule $q$ - is time constant, we can define

$$
V_{2}(D, \omega, \underline{c}, \mu):=u(D, \omega, \underline{c})+p W_{1}\left(\underline{c}^{A}, \mu\right)+(1-p) W_{1}\left(\underline{c}^{B}, \mu\right)
$$

We can hence define the function $W_{2}$ recursively as follows:

$$
W_{2}(\underline{c}, \mu):=\max _{D} q(D, \mu(D)) D+\beta \int_{\underline{\omega}}^{\infty} V_{2}(D, \omega, \underline{c}, \mu) f(\omega) d \omega .
$$

Given that we derived the recursive formulation of the three period problem, the extension to an arbitrary number of periods is immediate. The Bellman equation is as follows. For any level of debt $D$, endowment $\omega$ and initial type $\underline{c}^{i}$ we have

$$
V_{t}(D, \omega, \underline{c}, \mu)=u(D, \omega, \underline{c})+p W_{t-1}\left(\underline{c}^{A}, \mu\right)+(1-p) W_{t-1}\left(\underline{c}^{B}, \mu\right),
$$

where for all $\underline{c} \in\left\{c^{A}, c^{B}\right\}$ :

$$
W_{t-1}(\underline{c}, \mu)=\max _{D} q(D, \mu(D)) D+\beta \int_{\underline{\omega}}^{\infty} V_{t-1}(D, \omega, \underline{c}, \mu) f(\omega) d \omega .
$$

In other terms, if we exclude the fact that the number of remaining periods decreases, each period can be seen as any other one with different initial conditions. The default decision will be always determinate by the difference $\omega-D$, justifying the stationarity of the price schedule $q$. In our linear set-up, the initial conditions do not affect the shape of the indifference curve (as they only shift them in a parallel fashion). Both the full information optimal debt level, $D^{F I}=\frac{\beta^{\prime}-\beta}{\beta^{\prime} h}$, and the condition for the separating equilibrium debt level, $D^{-B}: U^{B}\left(D^{-B}, q\left(D^{-B}, 1\right)\right)=U^{B}\left(D^{F I}, q\left(D^{F I}, 0\right)\right)$ remain the same. The single crossing condition property is also maintained, hence, the solution to the problem between any two periods. 


\section{The ratings geography and time span}

\begin{tabular}{|c|c|c|c|c|c|c|c|}
\hline Country & Moody's & Fitch & $\mathbf{S} \& \mathbf{P}$ & Country & Moody's & Fitch & $\mathbf{S} \& \mathbf{P}$ \\
\hline Australia & 1980 & 1996 & 1980 & Malawi & - & 2003-09 & - \\
\hline Austria & 1980 & 1995 & 1980 & Malta & 1994 & 1997 & 1994 \\
\hline Belgium & 1980 & 1995 & 1989 & Mexico & 1991 & 1996 & 1993 \\
\hline Botswana & 2001 & - & 2001 & Morocco & 1999 & 2007 & 1998 \\
\hline Bulgaria & 1997 & 1998 & 1999 & Netherlands & 1986 & 1995 & 1989 \\
\hline Canada & 1980 & 1995 & 1980 & New Zealand & 1980 & 2000 & 1980 \\
\hline Cyprus & 1996 & 2002 & 1994 & Norway & 1980 & 1995 & 1980 \\
\hline Czech Republic & 1993 & 1996 & 1994 & Pakistan & 1995 & - & 1995 \\
\hline Denmark & 1980 & 1995 & 1981 & Papua New Guinea & 1999 & 1999 & 1999 \\
\hline Estonia & 1998 & 1998 & 1998 & Philippines & 1994 & 1999 & 1994 \\
\hline Fiji & 1997 & - & 2007 & Poland & 1995 & 1996 & 1995 \\
\hline Finland & 1980 & 1995 & 1980 & Portugal & 1987 & 1995 & 1989 \\
\hline France & 1980 & 1995 & 1980 & Romania & 1996 & 1996 & 1996 \\
\hline Germany & 1986 & 1995 & 1984 & Russia & 1997 & 1997 & 1997 \\
\hline Ghana & - & 2004 & 2004 & Seychelles & - & 2010 & 2007-09 \\
\hline Greece & 1991 & 1996 & 1989 & Singapore & 1990 & 1999 & 1989 \\
\hline Guatemala & 1998 & 2006 & 2002 & Slovak Republic & 1995 & 1997 & 1994 \\
\hline Honduras & 1999 & - & 2009 & Slovenia & 1996 & 1997 & 1996 \\
\hline Hungary & 1990 & 1996 & 1992 & South Africa & 1995 & 1995 & 1995 \\
\hline Iceland & 1989 & 2000 & 1989 & Spain & 1988 & 1995 & 1989 \\
\hline India & 1988 & 2000 & 1991 & Sri Lanka & 2011 & 2006 & 2006 \\
\hline Ireland & 1988 & 1995 & 1989 & Sweden & 1980 & 1995 & 1980 \\
\hline Italy & 1987 & 1995 & 1989 & Switzerland & 1982 & 1995 & 1989 \\
\hline Jamaica & 1998 & 2007 & 2000 & Thailand & 1990 & 1998 & 1989 \\
\hline Japan & 1982 & 1995 & 1980 & Trinidad and Tobago & 1993 & - & 1996 \\
\hline Korea & 1987 & 1996 & 1989 & Uganda & - & 2005 & 2009 \\
\hline Latvia & 1998 & 1998 & 1997 & United Kingdom & 1980 & 1995 & 1980 \\
\hline Lithuania & 1997 & 1997 & 1997 & United States & 1980 & 1995 & 1980 \\
\hline Luxembourg & 1990 & 1995 & 1995 & Venezuela & 1980 & 1998 & 1980 \\
\hline
\end{tabular}




\section{J Yield Events}

\begin{tabular}{lcllllll}
\multicolumn{4}{l}{} & NEGATIVE & & \multicolumn{4}{c}{ POSITIVE } \\
Country & Year & Country & Year & Country & Year & Country & Year \\
Czech Republic & 2003 & Pakistan & 1992 & Cyprus & 2006 & New Zealand & 1992 \\
Greece & 2010 & Portugal & 2011 & Ethiopia & 1987 & Norway & 1993 \\
Honduras & 1994 & South Africa & 1988 & Honduras & 1997 & Norway & 2004 \\
Honduras & 1996 & Sri Lanka & 1991 & Italy & 1984 & Norway & 2009 \\
Iceland & 2008 & Switzerland & 1994 & Japan & 1992 & Pakistan & 2003 \\
Jamaica & 1985 & Switzerland & 1999 & Japan & 1997 & Seychelles & 2003 \\
Jamaica & 1990 & Switzerland & 2003 & Japan & 1998 & Singapore & 2007 \\
Japan & 1990 & Thailand & 2004 & Japan & 2001 & Slovenia & 1993 \\
Japan & 1999 & Uganda & 1984 & Japan & 2007 & Slovenia & 1994 \\
Lithuania & 2009 & Uganda & 1985 & Korea & 1981 & Solomon Islands & 2004 \\
Luxembourg & 2006 & Uganda & 1986 & Korea & 1982 & Solomon Islands & 2005 \\
Malawi & 1995 & Uganda & 1989 & Korea & 1983 & Switzerland & 2000 \\
New Zealand & 1996 & United States & 2005 & Latvia & 2011 & Switzerland & 2002 \\
Norway & 1998 & & & Lithuania & 2010 & Switzerland & 2008 \\
& & & & Luxembourg & 1988 & Switzerland & 2011 \\
& & & & Mexico & 2001 & Thailand & 1987 \\
& & & & Namibia & 2001 & Vanuatu & 1989 \\
& & & & Nepal & 1991 & Vanuatu & 2008
\end{tabular}

\section{K Dataset: definition of variables}

General government gross debt (Debt, \% GDP): Gross debt consists of all liabilities that require payment or payments of interest and/or principal by the debtor to the creditor at a date or dates in the future. This includes debt liabilities in the form of SDRs, currency and deposits, debt securities, loans, insurance, pensions and standardized guarantee schemes, as well as other accounts payable (World Economic Outlook 2013, WEO13).

General government net lending/ borrowing (Net lending, \% GDP): Net lending $(+) /$ borrowing $(-)$ is calculated as revenue minus total expenditure. It is also equal to net acquisition of financial assets minus net incurrence of liabilities (WEO13).

General government primary net lending/ borrowing (Primary surplus, \% GDP): Primary net lending/ borrowing is net lending $(+) /$ borrowing $(-)$ plus net interest payable/ paid (interest expense minus interest revenue) (WEO13).

General government structural balance $(C A P B$, national currency): The structural budget balance refers to the general government cyclically adjusted balance adjusted for nonstructural elements beyond the economic cycle. These include temporary financial sector and asset price movements as well as one-off, or temporary, revenue or expenditure items. The cyclically adjusted balance is the fiscal balance adjusted for the effects of the economic cycle (WEO13).

General government structural balance $(\boldsymbol{C A P B}, \%$ potential GDP): The structural budget balance refers to the general government cyclically adjusted balance adjusted 
for nonstructural elements beyond the economic cycle. These include temporary financial sector and asset price movements as well as one-off, or temporary, revenue or expenditure items. The cyclically adjusted balance is the fiscal balance adjusted for the effects of the economic cycle (WEO13).

General government total expenditure (Expenditure, \% GDP): Total expenditure consists of total expense and the net acquisition of non-financial assets (WEO13).

GDP corresponding to fiscal year, current prices ( $G D P$, billions of national currency): Gross domestic product corresponding to fiscal year is the country's GDP based on the same period during the year as their fiscal data. In the case of countries whose fiscal data are based on a fiscal calendar (e.g., July to June), this series would be the country's GDP over that same period. For countries whose fiscal data are based on a calendar year (i.e., January to December), this series will be the same as their GDP in current prices (WEO13).

GDP growth (Growth, \%): author's own calculation applying the formula $\frac{G D P_{t}-G D P_{t-1}}{G D P_{t}}$ to the GDP series corresponding to fiscal year (current prices).

GDP per capita, constant prices ( GDPpc, units of national currency): GDP is expressed in constant national currency per person. Data are derived by dividing constant price GDP by total population (WEO13).

\section{First stage IV regressions}

Table 10: OLS with robust standard errors

\begin{tabular}{lcccc}
\hline \hline & Net lending & Primary surplus & CAPB & Expenditure \\
\hline & \multicolumn{4}{c}{ Corr $_{t-1}$} \\
\hline News $_{t-1}$ & $0.00222^{* * *}$ & $0.00213^{* * *}$ & $0.00214^{* * *}$ & $0.00222^{* * *}$ \\
& $(0.000268)$ & $(0.000285)$ & $(0.000290)$ & $(0.000267)$ \\
& & & & \\
MCO $_{t-1}$ & $-0.000394^{*}$ & -0.000365 & $-0.000480^{*}$ & -0.000383 \\
& $(0.000237)$ & $(0.000249)$ & $(0.000258)$ & $(0.000237)$ \\
\hline $\mathrm{N}$ & 611 & 541 & 513 & 611 \\
$\mathrm{R}$-square & 0.539 & 0.567 & 0.547 & 0.540 \\
$\mathrm{~F}$ & 11.35 & 12.01 & 11.39 & 11.37 \\
\hline \hline
\end{tabular}

Standard errors in parentheses

${ }^{*} p<0.1,{ }^{* *} p<0.05,{ }^{* * *} p<0.01$ 


\section{Robustness check for contagion}

Table 11: OLS with robust standard errors

\begin{tabular}{|c|c|c|c|c|}
\hline & Net lending & Primary surplus & CAPB & Expenditure \\
\hline Yield Shocks ${ }_{t-1}$ & $\begin{array}{c}0.459^{* * * *} \\
(0.157)\end{array}$ & $\begin{array}{c}0.468 * * * \\
(0.166)\end{array}$ & $\begin{array}{c}0.249 * * \\
(0.122)\end{array}$ & $\begin{array}{c}-0.265^{* *} \\
(0.128)\end{array}$ \\
\hline Net lending ${ }_{t-1}$ & $\begin{array}{c}0.724^{* * * *} \\
(0.0426)\end{array}$ & & & \\
\hline Primary surplus $_{t-1}$ & & $\begin{array}{c}0.753^{* * *} \\
(0.0410)\end{array}$ & & \\
\hline $\mathrm{CAPB}_{t-1}$ & & & $\begin{array}{c}0.720 * * * \\
(0.0554)\end{array}$ & \\
\hline Expenditure $_{t-1}$ & & & & $\begin{array}{c}0.770 * * * \\
(0.0344)\end{array}$ \\
\hline $\operatorname{Debt}_{t-1}$ & $\begin{array}{c}0.0198 \\
(0.0123)\end{array}$ & $\begin{array}{c}0.0510^{* * *} \\
(0.0133)\end{array}$ & $\begin{array}{c}0.00951 \\
(0.0107)\end{array}$ & $\begin{array}{c}0.00266 \\
(0.0123)\end{array}$ \\
\hline Debt $_{t-1}^{2}$ & $\begin{array}{c}-0.000161^{* * *} \\
(0.0000470)\end{array}$ & $\begin{array}{c}-0.000249^{* * *} \\
(0.0000498)\end{array}$ & $\begin{array}{c}-0.0000845^{*} \\
(0.0000488)\end{array}$ & $\begin{array}{c}0.0000686 \\
(0.0000477)\end{array}$ \\
\hline $\log \mathrm{GDP}_{t-1}$ & $\begin{array}{c}-1.784^{* *} \\
(0.816)\end{array}$ & $\begin{array}{c}-2.430 * * * \\
(0.812)\end{array}$ & $\begin{array}{c}-2.424^{* *} \\
(1.150)\end{array}$ & $\begin{array}{c}1.177 \\
(0.794)\end{array}$ \\
\hline $\log \mathrm{GDPpc}_{t-1}$ & $\begin{array}{c}1.881 \\
(1.635)\end{array}$ & $\begin{array}{l}4.002^{* *} \\
(1.894)\end{array}$ & $\begin{array}{c}2.876 \\
(2.042)\end{array}$ & $\begin{array}{c}0.858 \\
(1.585)\end{array}$ \\
\hline Growth $_{t-1}$ & $\begin{array}{c}5.182 \\
(3.936)\end{array}$ & $\begin{array}{c}2.142 \\
(4.450)\end{array}$ & $\begin{array}{c}8.253 \\
(6.371)\end{array}$ & $\begin{array}{l}-5.805 \\
(3.930)\end{array}$ \\
\hline Rating $_{t-1}$ & $\begin{array}{c}-0.116^{* *} \\
(0.0473)\end{array}$ & $\begin{array}{c}-0.0976^{*} \\
(0.0550)\end{array}$ & $\begin{array}{l}-0.0594 \\
(0.0479)\end{array}$ & $\begin{array}{l}0.0781^{*} \\
(0.0431)\end{array}$ \\
\hline $\log$ yields $_{t-1}$ & $\begin{array}{c}0.00670 \\
(0.455)\end{array}$ & $\begin{array}{c}0.617 \\
(0.535)\end{array}$ & $\begin{array}{c}0.827 \\
(0.583)\end{array}$ & $\begin{array}{c}0.441 \\
(0.407)\end{array}$ \\
\hline Country & Yes & Yes & Yes & Yes \\
\hline Year FE & Yes & Yes & Yes & Yes \\
\hline $\mathrm{N}$ & 748 & 658 & 598 & 748 \\
\hline R-square & 0.849 & 0.845 & 0.846 & 0.979 \\
\hline $\mathrm{F}$ & 41.58 & 43.36 & . & 661.5 \\
\hline
\end{tabular}

Standard errors in parentheses

${ }^{*} p<0.1,{ }^{* *} p<0.05,{ }^{* * *} p<0.01$ 


\section{N Regression by country groups}

Table 12: OLS with robust standard errors

\begin{tabular}{lcccc}
\hline \hline & $(1)$ & $(2)$ & $(3)$ & $(4)$ \\
Effect of a 1 unit change in Corr $_{t}$ in: & OECD & EU & PERIPHERALS & EM \\
\hline Net lending/borrowing & $-0.0284^{* * *}$ & $-0.0350^{* * *}$ & $-0.0770^{* *}$ & -0.0249 \\
& $(0.00885)$ & $(0.0112)$ & $(0.0333)$ & $(0.0233)$ \\
\hline $\mathrm{N}$ & 535 & 397 & 93 & 96 \\
$\mathrm{R}$-square & 0.823 & 0.765 & 0.741 & 0.761 \\
$\mathrm{~F}$ & 45.38 & 33.02 & 14.59 & 45.21 \\
\hline Primary balance & $-0.0258^{* * *}$ & $-0.0315^{* * *}$ & $-0.0722^{* *}$ & -0.0272 \\
& $(0.00863)$ & $(0.0107)$ & $(0.0319)$ & $(0.0222)$ \\
\hline $\mathrm{N}$ & 534 & 396 & 92 & 96 \\
$\mathrm{R}$-square & 0.752 & 0.712 & 0.733 & 0.731 \\
$\mathrm{~F}$ & 39.80 & 32.87 & 13.86 & 44.28 \\
\hline Potential structural balance & $-0.0107^{*}$ & -0.0105 & $-0.0574^{* *}$ & -0.0220 \\
& $(0.00645)$ & $(0.00856)$ & $(0.0243)$ & $(0.0182)$ \\
\hline $\mathrm{N}$ & 535 & 397 & 93 & 96 \\
$\mathrm{R}$-square & 0.848 & 0.852 & 0.857 & 0.853 \\
$\mathrm{~F}$ & 59.24 & 43.61 & 22.59 & 70.95 \\
\hline Government spending & $0.0246^{* * *}$ & $0.0278^{* *}$ & 0.0425 & 0.0246 \\
& $(0.00906)$ & $(0.0122)$ & $(0.0282)$ & $(0.0310)$ \\
\hline $\mathrm{N}$ & 535 & 397 & 93 & 96 \\
$\mathrm{R}$-square & 0.942 & 0.928 & 0.840 & 0.975 \\
$\mathrm{~F}$ & 399.3 & 249.0 & 62.09 & 302.8 \\
\hline \hline Stang
\end{tabular}

Standard errors in parentheses

${ }^{*} p<0.1,{ }^{* *} p<0.05,{ }^{* * *} p<0.01$ 


\section{O Introduction of a common debt limit}

In this section I analyze the effect of setting an exogenous common debt limit. This policy only has an effect when the debt ceiling $\bar{D}_{2}$ is lower than type B's full information allocation $D_{2}^{F I}$, as in figure 7 . Suppose the equilibrium is the separating one $e^{*}$. Once the debt ceiling is introduced, type B is not allowed to choose its optimal debt level because it would violate the fiscal rule. In a separating equilibrium under the new debt ceiling rule, type B chooses the highest amount of debt possible, $\bar{D}_{2}$, as depicted in figure 8. But this gives type $\mathrm{B}$ a lower utility, thereby forcing type A to choose an even lower amount of debt than $D_{2}^{-B}$. Type A needs to implement more austerity in order to avoid imitation from B because the outside option for B has become worse. Both types are worse off, even though the riskiness of debt improves because the sovereigns have a lower default probability.

Nevertheless, the introduction of a debt limit might let the separating equilibrium be defeated. For instance, the pooling equilibrium at $\bar{D}_{2}$ in figure 9 makes both types better off, thus defeating the separating equilibrium. Compared with the initial equilibrium $e^{*}$ in figure 7 , however, every country type loses. This can be seen by comparing the utility levels of type $\mathrm{A}$ and $\mathrm{B}$ with the equilibrium allocations from figure 7 represented by the dotted lines. Moreover, type B's default premium decreases but A's increases, as the arrows on the vertical axis show, thus the overall probability of default may increase or decrease. All countries can be made worse off by the introduction of a debt ceiling, which also fails to improve the riskiness of debt. 


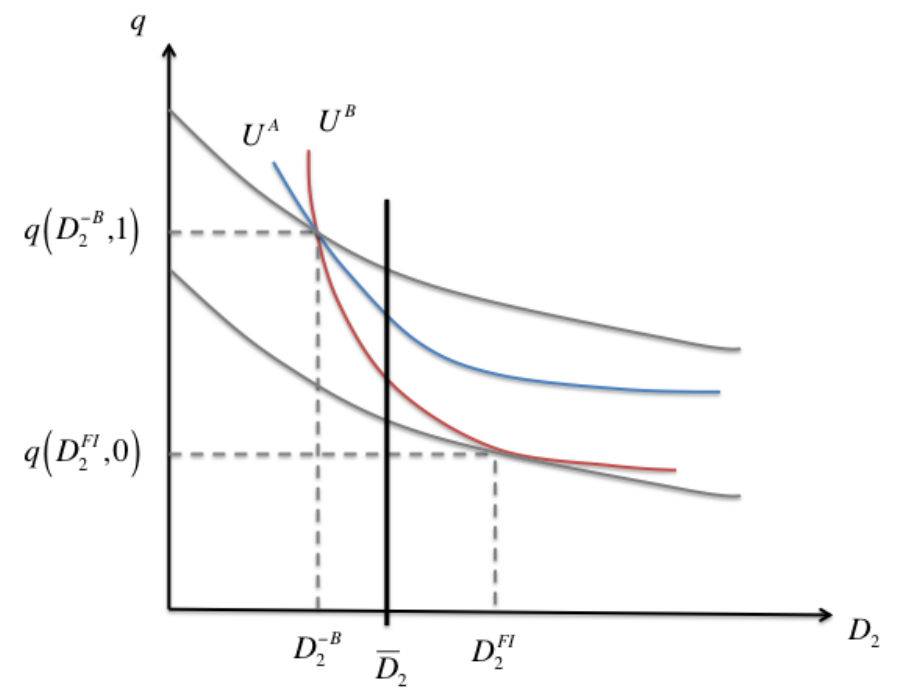

Figure 7: A common debt ceiling at $\bar{D}_{2}$.
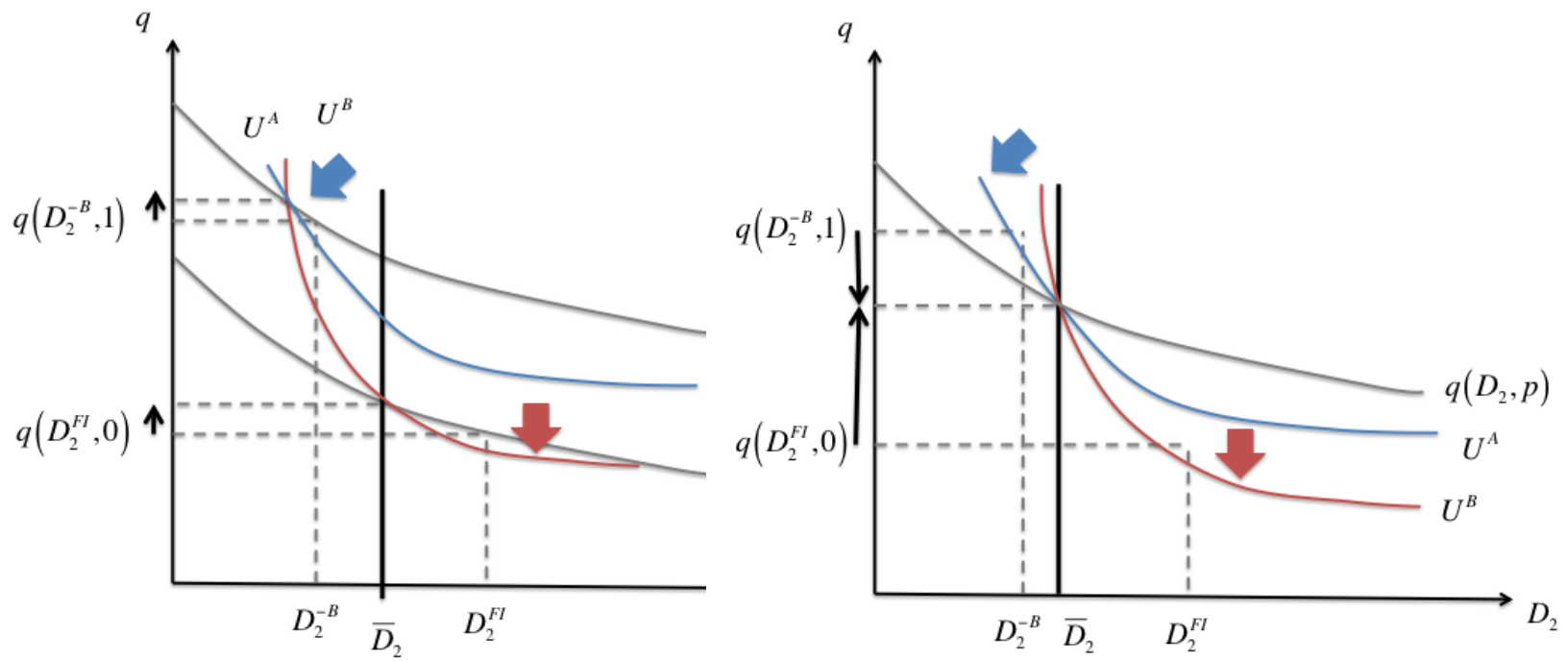

Figure 8: Separating equilibrium with a Figure 9: Pooling equilibrium with a common common debt ceiling. debt ceiling. 